\title{
Ngrams and Engrams: The Use of Structural and Conceptual Features to Discriminate Between English Translations of Religious Texts
}

\begin{abstract}
We present experiments using the Linguistic Inquiry and Word Count (LIWC) program, a closed-class keyword (CCK) analysis and a Correspondence Analysis (CA) to examine whether the Scientology texts of L. Ron Hubbard are linguistically and conceptually like those of other religions. A Kruskal-Wallis test comparing the frequencies of LIWC category keywords in the Scientology texts and the English translations of the texts of five other religions showed that there were 18 categories for which the Scientology texts differed from the others, and between one and 17 for the other religions. In the CCK experiment, keywords typical of each religion were found, both by comparing the religious texts with each other and with the Brown corpus of general English. The most typical keywords were looked up in a concordancer, and tagged according to conceptual category. The set of categories found for the Scientology texts showed little overlap with those found for the others. Our CA experiments produced fairly clear clusters of texts by religion. Scientology texts were seen at one pole on the first factor, with Christian and Islamic texts at the other. It appears that in several ways the Scientology texts are dissimilar to the texts of some of the world's major religions.
\end{abstract}

\section{Introduction}

Since its conception in the 1950s, the Church of Scientology has remained a subject of controversy and public interest. Recently, its status in the UK has been the focus of media attention once again. A young British couple, both Scientologists, wished to be married in the church they regularly attend in London, but were denied the right on the basis that - as was 
ruled in a similar case in 1970 - such a church is not considered "a place of meeting for religious worship” (BBC News, 2013). On the 11th December 2013, following a five-year legal battle and extensive media coverage, the Supreme Court of the UK ruled in the couple's favour and "redefined religion in law”, thus recognising Scientology as a religion and enabling the couple to be married (Bingham, 2013). The justification for overruling the previous decision was that, by adopting “a comparative approach”, Scientology can “be analogised to accepted religions”, naming Buddhism as another example of a religion which does not "recognise a supreme deity" ( $R v$ Registrar General of Births, Deaths and Marriages [2013] UKSC 77, pp. 13-16).

While Scientology has religious status in at least fifteen countries (including the US, Australia, Sweden and the UK), it is rejected by others (France, Chile and Israel, among others) as a 'cult' (Sanderson, 2013). It has been heavily criticised in numerous books, articles and reports, to the extent that its members claim to be "persecuted" (Enquete Commission, 1998). Evidently, its international footing as an accepted religion is far from established. From a legal perspective, the status of Scientology is relevant for financial and administrative reasons: religious organisations have charitable status and are exempt from tax in the US and the UK, for example. From a linguistic perspective, it is interesting to consider the status - or genre - of Scientology as reflected by the language of its scriptures. Do Scientology texts look, or sound, like those of more familiar religions? By taking a “comparative approach”, does a corpus analysis of religious texts reach the same conclusions as the judges of the Supreme Court?

To investigate this question, Scientology texts are compared against other religious texts using the program Linguistic Inquiry and Word Count, or LIWC (Pennebaker et al., 2007), a closed-class keywords analysis (Groom, 2010) and a correspondence analysis. Section 2 therefore gives a brief overview of Scientology and some examples of religious text 
analysis, followed by the details of the three methodologies and their respective findings in Section 3. Section 4 concludes the paper.

\section{Background}

Scientology was developed by science fiction writer L. Ron Hubbard in the late 1940s, with the first church being established in Los Angeles in 1954. Its name is taken from the Latin 'scio' ('knowing') and the Greek 'logos' ('study of'), and it is defined on the Scientology.org website as "a twenty-first century religion” which "offers a pathway to greater freedom” (Scientology.org, 2014). Its basis lies in the study of 'Dianetics', a branch of science also developed by Hubbard, in conjunction with his theories on 'thetans' (souls) and the need to rid them of their 'engrams' (traumatic events) through 'auditing' (psychotherapy). Once free of these engrams, a Scientologist progresses from the status of 'preclear' to 'clear', with the ultimate goal of becoming an 'Operating Thetan' (or 'OT'), one whose thetan is "at cause over mental matter, energy, space and time” (Hubbard, 1954). There are progressive levels of Operating Thetan, which one must ascend through to reach true enlightenment. This process is somewhat comparable to 'Visuddhimagga' (the 'path to purification') in Theravada Buddhism, and also the general concepts of 'Nirvana' in Buddhist religions and 'Moksha' in Hinduism and Jainism (Murray, 2014; Kent, 1996). Ultimately, Scientology aims to alleviate the problems of modern life using a combination of scientific understanding and spiritual engagement, focusing on the self, rather than a particular deity.

Although Buddhism is cited as the religion most comparable with Scientology, Hubbard also maintained that its beliefs are rooted in those of Hinduism and Taoism (Lewis, 2009: 250), crediting the Hindu Vedas as inspiration for the Scientology term 'Knowingness', or 'self-determined knowledge' (Kent, 2006). That Scientology is comparable with 'Eastern' religions is a view supported by religious scholars Wallis (1976) and Wilson (1998) (cited in 
Lewis, 2009). Wallis (1976: 246) even identifies Scientology as “an extension of certain central features of [Western religious traditions]” (cited in Hexham, 1997). Based on these findings, Scientology is approached, in this paper, as a religion, and the hypothesis adopted for the purpose of this study is the judgment made by the Supreme Court in December: Scientology is considered a religion "by process of analogy, looking at familiar religions as models” ( $R v$ Registrar General of Births, Deaths and Marriages, [2013] UKSC 77). As opposed to comparing theological content, it is hoped that an analysis of the language alone will help to shed some light on the place of Scientology with relation to the world's major religions. If Scientology is indeed similar to religions such as Buddhism and Hinduism, then we might expect to see some similarities in linguistic tendencies and in the concepts encoded in the language of their religious scriptures ${ }^{1}$.

Two recent studies which deal with the computational analysis of stylistics and religion are Štajner and Mitkov (2012) and Erwin and Oakes (2012). The former used machine-learning algorithms to measure diachronic changes in linguistic features among the religious sections of the 'Brown family' of corpora. The outcome was that, in comparison with British English texts discussing religion (from the FLOB and LOB corpora), there was little difference in American English texts discussing religion (from the Brown and Frown corpora) between 1961 and 1991, but there was a significant drop in the use of a number of 'stop-words', which suggests that closed-class or function words could be a fruitful area of investigation ${ }^{2}$. The paper by Erwin and Oakes (2012) used a correspondence analysis of the New Testament (in its original Greek) to test for similarities and differences between the language of different biblical texts. They found that texts which are believed to be authored by different people were indeed distinctly separate in their clusters, which gives weight to the

\footnotetext{
${ }^{1}$ When translated into contemporary English. Translations are problematic from the perspective of the analysis of style but, as the original texts are written in different languages and in different time periods, the use of contemporary English translations was unavoidable in this study.

${ }^{2}$ The texts mostly concern Christianity. They are not 'religious texts' as such, but texts about religion.
} 
idea of applying linguistic analysis to religious texts in order to prove or disprove particular theories. Oakes (2014, Chapter 4) also gives several examples of detailed stylometric analysis of religious texts (Christian, Mormon and Islamic), concluding that sophisticated computational approaches to this topic complement, but should not replace, traditional close readings of religious texts.

\section{Methodologies and Results}

\subsection{The data}

First, any available Scientology texts written by L. Ron Hubbard in the 1950s and 1960s were located, downloaded and cleaned. ${ }^{3}$ On the recommendation of the Supreme Court judgment, our hypothesis is that Scientology is a religion, by comparison with other religions. These texts are therefore considered the scriptures of Scientology and form the 'Scientology' corpus. The 'Religion' section of the Brown corpus might seem an ideal candidate for comparison, since it represents a variety of religions and all of the texts were written during the 1960s in America, making them comparable with the writings of L. Ron Hubbard. However, this subcorpus is not so much 'religious texts' as 'texts about religion'; it is comprised of samples of books and critiques of religious concepts. Therefore, it was necessary to build our own corpora of scriptures from other religions. The five major world religions of Christianity, Islam, Buddhism, Hinduism and Sikhism were selected, and English translations of some of the scriptures of these religions, published between 1930 and 1980, were located, downloaded and cleaned as before. The Brown corpus was also downloaded and used as a general reference corpus ${ }^{4}$. No tagging or parsing was carried out. Tables 1 and 2 give information on the sizes and compositions of the two main corpora used. As can be

\footnotetext{
${ }^{3}$ Page numbers, chapter numbers and tables of contents were stripped out.

${ }^{4}$ The Brown corpus was chosen as it represents general 1960s American English, and therefore serves as an ideal reference corpus for the Scientology texts in particular
} 
seen, the religious subcorpora are small, but in some cases it was difficult to obtain much relevant data; out of the texts which were freely available, many were simply commentaries rather than translations, and the majority of modern English translations were produced in the $19^{\text {th }}$ century which could have skewed the comparison of style.

\begin{tabular}{|l|l|l|}
\hline \multicolumn{3}{|c|}{ RELIGIOUS CORPUS } \\
\hline $\begin{array}{l}\text { Subcorpus } \\
\text { (abbr.) }\end{array}$ & Source(s) & $\begin{array}{l}\text { No. of tokens } \\
\text { (types) }\end{array}$ \\
\hline $\begin{array}{l}\text { Buddhist } \\
\text { texts } \\
\text { (BUD) }\end{array}$ & $\begin{array}{l}\text { Esoteric Teachings of the Tibetan Tantra by C. A. Musés (1961) } \\
\text { [online]. Available at: http://sacred-texts.com/bud/ett/index.htm }\end{array}$ & $\begin{array}{l}59,780 \\
(5,520)\end{array}$ \\
\hline $\begin{array}{l}\text { Sikh texts } \\
\text { (SIK) }\end{array}$ & $\begin{array}{l}\text { Translation of the Guru Granth Sahib by Manmohan Singh } \\
\text { (1960). [online]. Available at: } \\
\text { http://www.gurbanifiles.org/translations/index.htm }\end{array}$ & $\begin{array}{l}64,735 \\
(4,182)\end{array}$ \\
\hline $\begin{array}{l}\text { Hindu texts } \\
\text { (HIN) }\end{array}$ & $\begin{array}{l}\text { The Crest-Jewel of Wisdom and other writings of Śankarâchârya: } \\
\text { translation and commentaries by Charles Johnston (1946). } \\
\text { [online]. Available at: http://sacred-texts.com/hin/cjw/index.htm } \\
\text { The Transmigration of the Seven Brahmans: a Translation from } \\
\text { the Harivansa of Langois by Henry David Thoreau, ed. Arthur } \\
\text { Christy (1932). [online]. Available at: http://sacred- } \\
\text { texts.com/hin/tsb/index.htm }\end{array}$ & $\begin{array}{l}51,862 \\
(5,853)\end{array}$ \\
\hline $\begin{array}{l}\text { Islamic } \\
\text { texts (ISL) }\end{array}$ & $\begin{array}{l}\text { The Koran Interpreted: A Translation by A. J. Arberry (1955) } \\
\text { [online]. Available at: https://archive.org/stream/QuranAJArberry/ } \\
\text { Quran-A\%20J\%20Arberry djvu.txt }\end{array}$ & $\begin{array}{l}151,264 \\
(6,689)\end{array}$ \\
\hline $\begin{array}{l}\text { Christian } \\
\text { texts (CHR) }\end{array}$ & $\begin{array}{l}\text { The New American Standard Bible [online]. Available at: } \\
\text { http://www.biblegateway.com/versions/New-American-Standard- } \\
\text { Bible-NASB/ }\end{array}$ & $\begin{array}{l}205,940 \\
(9,118)\end{array}$ \\
\hline $\begin{array}{l}\text { Scientology } \\
\text { texts (SCI) }\end{array}$ & $\begin{array}{l}\text { Scientology 8-80 (1952); Scientology 8-8008 (1952); The Creation } \\
\text { of Human Ability (1954); Dianetics 55! (1955); Scientology: the } \\
\text { Fundamentals of Thought (1956); Problems of work (1956); } \\
\text { Scientology: a New Slant on Life (1965). All texts by L. Ron } \\
\text { Hubbard. Available at: } \\
\text { http://www.bridgepub.com/store/catalog/basics-books/index.html }\end{array}$ & $\begin{array}{l}267,965 \\
(12,295)\end{array}$ \\
\hline TOTAL & \begin{tabular}{l}
$\mathbf{8 0 1 , 5 4 6}$ \\
\hline
\end{tabular} & \\
\hline
\end{tabular}

Table 1: Religious corpus information 


\begin{tabular}{|l|l|l|}
\hline \multicolumn{3}{|c|}{ BROWN CORPUS } \\
\hline Subcorpus & $\begin{array}{l}\text { No. of } \\
\text { source } \\
\text { books }\end{array}$ & $\begin{array}{l}\text { No. of tokens } \\
\text { (types) }\end{array}$ \\
\hline A. PRESS: Reportage & 44 & $89,271(13,311)$ \\
\hline B. PRESS: Editorial & 27 & $35,958(8,315)$ \\
\hline C. PRESS: Reviews & 17 & $55,380(9,640)$ \\
\hline D. RELIGION & 17 & $74,466(11,264)$ \\
\hline E. SKILL AND HOBBIES & 36 & $73,466(11,264)$ \\
\hline F. POPULAR LORE & 48 & $98,695(13,750)$ \\
\hline G. BELLES-LETTRES & 75 & $154,277(17,381)$ \\
\hline H. MISCELLANEOUS & 30 & $62,027(7,835)$ \\
\hline J. LEARNED & 80 & $162,556(15,814)$ \\
\hline K. FICTION: General & 29 & $59,592(8,975)$ \\
\hline L. FICTION: Mystery & 24 & $49,886(6,653)$ \\
\hline M. FICTION: Science & 6 & $12,357(3,179)$ \\
\hline N. FICTION: Adventure & 29 & $60,223(8,506)$ \\
\hline P. FICTION: Romance & 29 & $60,609(8,116)$ \\
\hline R. HUMOR & 9 & $18,777(4,917)$ \\
\hline TOTAL & & $\mathbf{1 , 0 2 7 , 8 2 6}$ \\
\hline
\end{tabular}

Table 2: Brown corpus information

The corpora in their raw forms were of varying sizes and were made up of different numbers of source texts. In order to create more data points for analysis, and to improve consistency of size, each of the religious subcorpora were split into chunks of 1000 words, and the Brown subcorpora into chunks of 500 words ${ }^{5}$, apart from the final chunk of each corpus which was smaller. It was necessary to split the text into these samples as input for the correspondence analysis, and also to help identify atypical sections of the texts as a whole.

\subsection{Findings}

The hypothesis - that Scientology can be deemed religious by comparison with other religions - was submitted to three tests. The first test was a LIWC (pronounced 'Luke’) analysis, which makes use of the word-counting software Linguistic Inquiry and Word Count developed by James Pennebaker and colleagues at the University of Texas (2007). The

\footnotetext{
${ }^{5}$ Some of the subsections of the Brown corpus are quite small; to split them into 1000 -word chunks would have meant as few as 13 data points for some sections.
} 
second test was a closed-class keywords (CCK) analysis as championed by Gledhill (2000) and Groom (2010). Finally, some correspondence analysis (CA) experiments were carried out, by plotting text samples against the frequencies of particular linguistic features: in this case, a combination of LIWC features and commonly occurring words. In the interests of clarity, the details of the three methodological processes are presented with their respective findings in the following subsections.

\subsubsection{The LIWC analysis}

A basic LIWC analysis was chosen as a quantitative starting point to the investigation; it is a quick and easy method for computing scores for different features and highlighting differences between texts. Based in social psychology studies, LIWC works by reading each inputted text and counting how many words in that text match the words in its pre-defined dictionaries. It then produces a table of scores which reflect each 'dimension' as a percentage; for example, a score of 3.2 for posemo would mean that $3.2 \%$ of that particular text is made up of words which match LIWC's 'positive emotion words' dictionary. LIWC has been used in a number of applications, but particularly in psychology; for example, by comparing the scores of the writing of mental health patients over time, Pennebaker (1997) was able to track changes in cognitive and emotional processes and pinpoint potential triggers for recovery. It has also been used in author profiling (Mairesse and Walker, 2006) and first language profiling (Torney et al., 2012), among others. Figure 1 gives examples of some of the words that make up the different LIWC dimensions ${ }^{6}$.

First, the raw (non-split) corpus data was processed using LIWC. Since there are about 60 LIWC features to be analysed, it was necessary to narrow them down into a smaller

\footnotetext{
${ }^{6}$ Taken from http://www.kovcomp.co.uk/wordstat/LIWC.html; see Appendix B for the full list of features. For this particular experiment, average word length, words per sentence, punctuation, numbers, and the features relating to spoken language (fillers, non-fluencies, etc.), were not observed.
} 
number of potentially salient features. In order to see whether, and how, Scientology texts differ from those of other religions, a 'difference score' was calculated by dividing the Scientology score by the average of all scores (Scientology’s included) and deducting 1.

Figure 2 represents all of these difference scores ${ }^{7}$.

\begin{tabular}{|c|c|c|c|}
\hline DIMENSION & EXAMPLES & DIMENSION & EXAMPLES \\
\hline Total pronouns & I, them, itself & Cognitive & cause, know, ought \\
\hline Personal pronouns & I, them, her & Insight & think, know, consider \\
\hline $\begin{array}{l}\text { Impersonal } \\
\text { pronouns }\end{array}$ & It, those & Causation & because, effect, hence \\
\hline Articles & a, an, the & Discrepancy & should, would, could \\
\hline Verbs & walk, went, see & Tentative & $\begin{array}{l}\text { maybe, perhaps, } \\
\text { guess }\end{array}$ \\
\hline Adverbs & very, really, quickly & Certainty & always, never \\
\hline Prepositions & with, above & Inhibition & block, constrain \\
\hline Conjunctions & but, whereas & Inclusive & with, and, include \\
\hline Negations & no, never, not & Exclusive & but, except, without \\
\hline Quantifiers & few, many, much & $\begin{array}{l}\text { Biological } \\
\text { Processes }\end{array}$ & eat, blood, pain \\
\hline Swear words & damn, fuck, piss & Body & ache, heart, cough \\
\hline Social Processes & talk, us, friend & Health & clinic, flu, pill \\
\hline Friends & pal, buddy, coworker & Sexuality & horny, love, incest \\
\hline Family & mom, brother, cousin & Ingestion & eat, swallow, taste \\
\hline Humans & boy, woman, group & Relativity & area, bend, exit, stop \\
\hline Affective Processes & happy, ugly, bitter & Motion & walk, move, go \\
\hline Positive Emotions & happy, pretty & Space & Down, in, thin \\
\hline Negative Emotions & hate, worthless, enemy & Time & hour, day, o’clock \\
\hline Anxiety & nervous, afraid, tense & Work & work, class, boss \\
\hline Anger & hate, kill, pissed & Achievement & try, goal, win \\
\hline Sadness & grief, cry, sad & Leisure & house, TV, music \\
\hline $\begin{array}{c}\text { Perceptual } \\
\text { Processes }\end{array}$ & see, touch, listen & Home & house, kitchen, lawn \\
\hline Seeing & view, s & Money & audit, casl \\
\hline Hearing & heard, listen, sound & Religion & altar, church, mosque \\
\hline Feeling & touch, hold, felt & Death & bury, coffin, kill \\
\hline
\end{tabular}

Figure 1: Some LIWC dimensions, with example words

\footnotetext{
${ }^{7}$ It should be noted that this deviation from the group average is taken to imply distinctiveness of Scientology texts from the group as a whole, but due to varying standard deviations it is merely used as a broad-brushstroke measure and does not accurately represent the differences between corpora.
} 
The eight dimensions with the largest differences, listed on the right-hand side of Figure 2, highlight possible avenues of further investigation. The data for these eight features are represented in the boxplots below to show more clearly the differences between, and similarities amongst, the religious corpora.

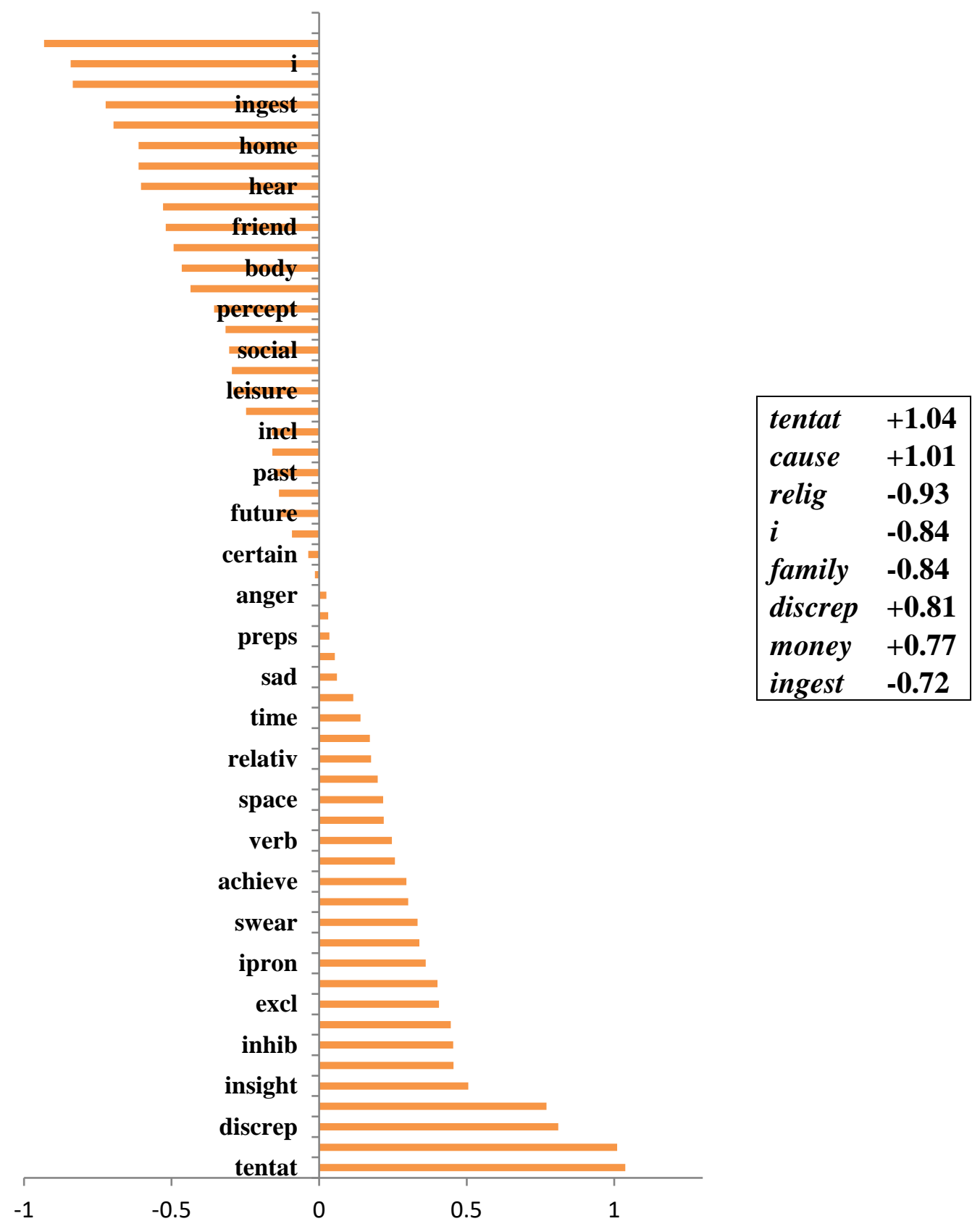

Figure 2: The difference scores for the Scientology corpus when compared against all of the religious texts 


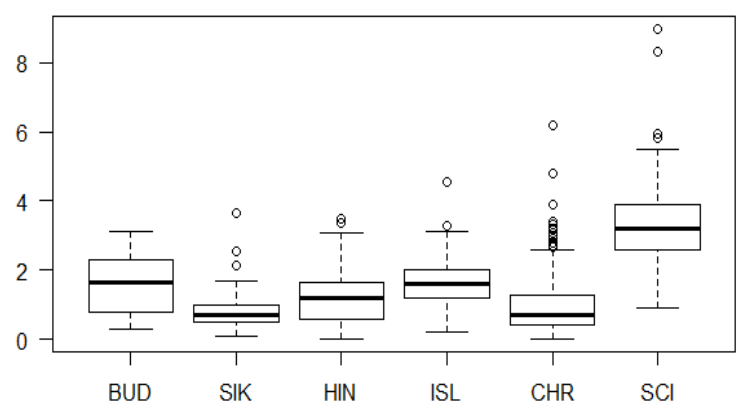

Figure 3: The LIWC scores for tentat

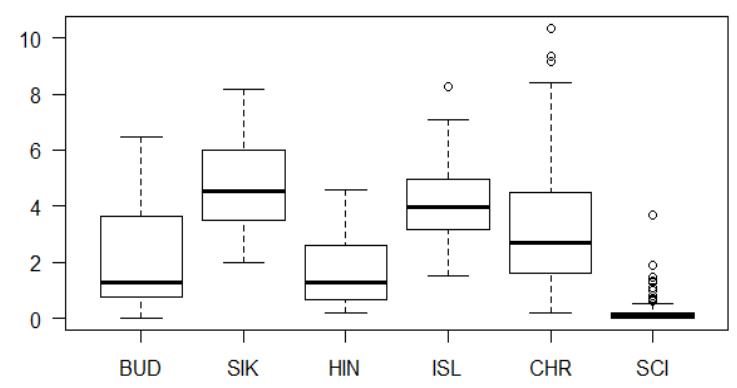

Figure 5: The LIWC scores for relig

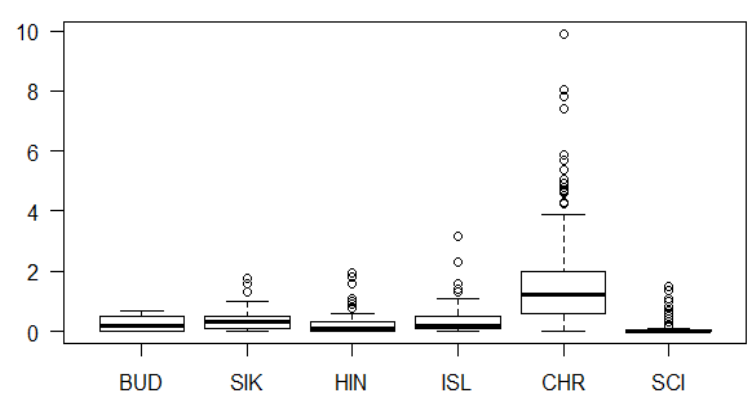

Figure 7: The LIWC scores for family

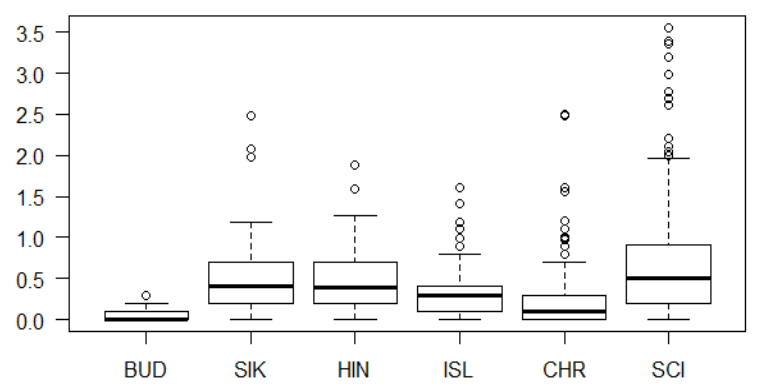

Fig. 9: The LIWC scores for money

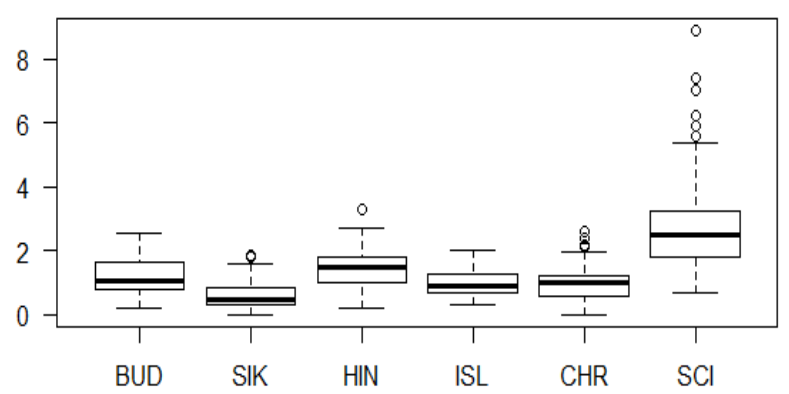

Figure 4: The LIWC scores for cause

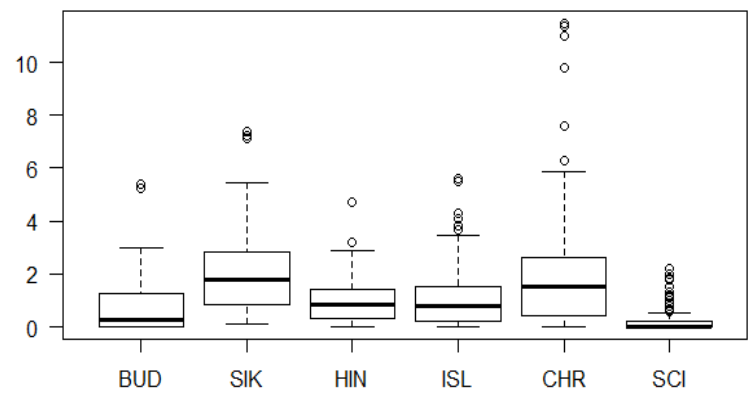

Figure 6: The LIWC scores for $i$

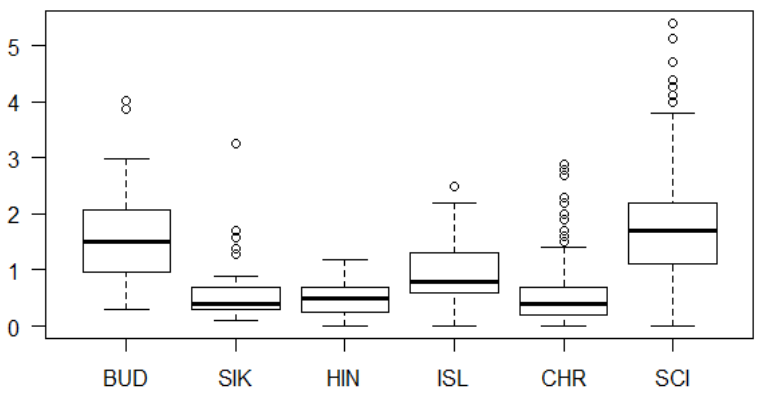

Figure 8: The LIWC scores for discrep

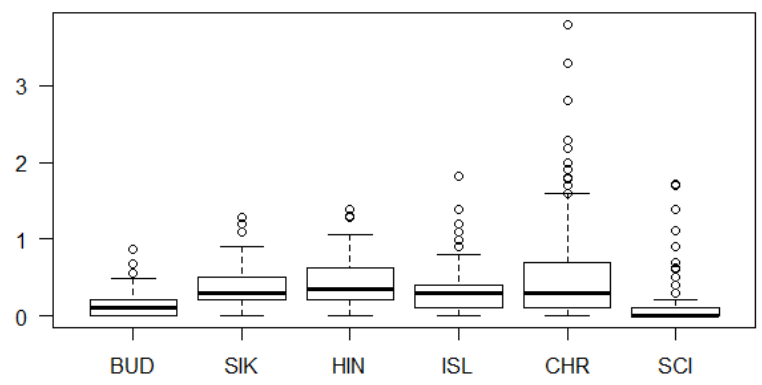

Fig. 10: The LIWC scores for ingest 
Immediately we can see that for the first four dimensions, tentat (tentative words), cause (causation words), relig (religious words), and $i$ (first-person singular pronouns), the Scientology texts do indeed behave quite differently from the others. The tentat score is particularly high for the Scientology texts due to the comparatively high frequency of "or", and in cause, the words "thus" and "control”. Most striking, and perhaps most salient in this case, is the relig boxplot. Looking at the words being matched, we see fairly predictable results for the five major-world-religion texts (“soul”, “Lord”, “God”, “Buddha”, and so on) and a few high-ranking religious terms for Scientology (“spirit”, “belief”, “faith”), but also some noisy hits: the inclusion of demon* in the 'religion' dictionary resulted in matches like “demonstrate”, “demonstrates”, and “demonstrated”, which falsely inflate the Scientology corpus score for relig. The family (family words) boxplot reveals that it is not Scientology which deviates from the norm, but Christianity, which explains the high difference score in Figure 2; as to be expected, the Christian texts are preoccupied with family and feature a range of family-member references, particularly “son” and “sons”.

Money (money words) is another problematic category: as a religion which revolves around the process of 'auditing', it is no wonder that the money score is relatively high for the Scientology texts. Other noisy results included “dimension” (due to dime*) and “Bill”, a name used in many of Hubbard's hypothetical dialogues. "Free” is another ambiguous 'money' word which features highly in the Scientology texts, and also the Hindu ones; there was only one reference to "free" in the sense of "free of charge" (found in the Scientology hits), with all others referring to notions of liberty ("set you free”, "free to”) and purity or safety ("free from”). Ingest (food and drink words) and discrep (discrepancy words) are interesting in that the Scientology texts do differ from the majority, but only to the same extent as the Buddhist texts do. While other religious texts mention the acts of eating and drinking, these are clearly not as important in the Buddhist and Scientology texts. As for 
discrep, we found that the Buddhist, Islamic and Scientology texts each had one particularly high-frequency word which inflated their scores: "if”, "should”, and “would”, respectively. These function words are examined in the following section.

If the Scientology texts are unlike any of the others in the cases of tentat, cause, relig and $i$, it begs the question of which genres they might instead be compared with. Below are the first four boxplots again, but this time extended to include the Brown corpus.

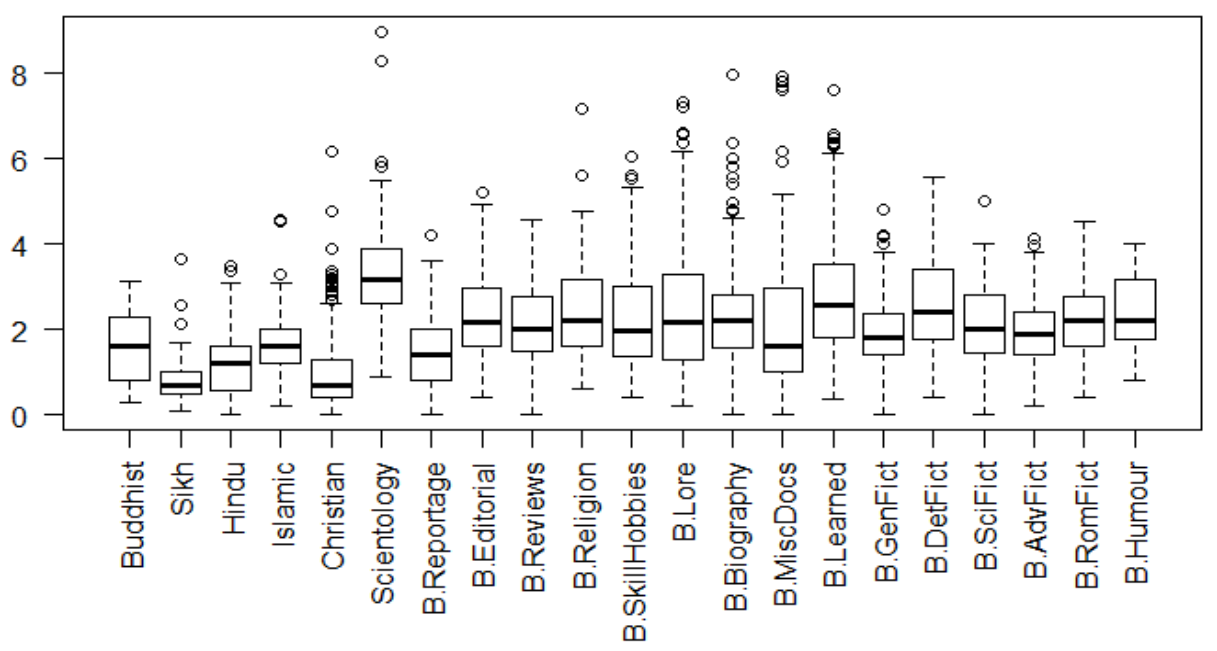

Figure 11: Extended LIWC scores for tentat

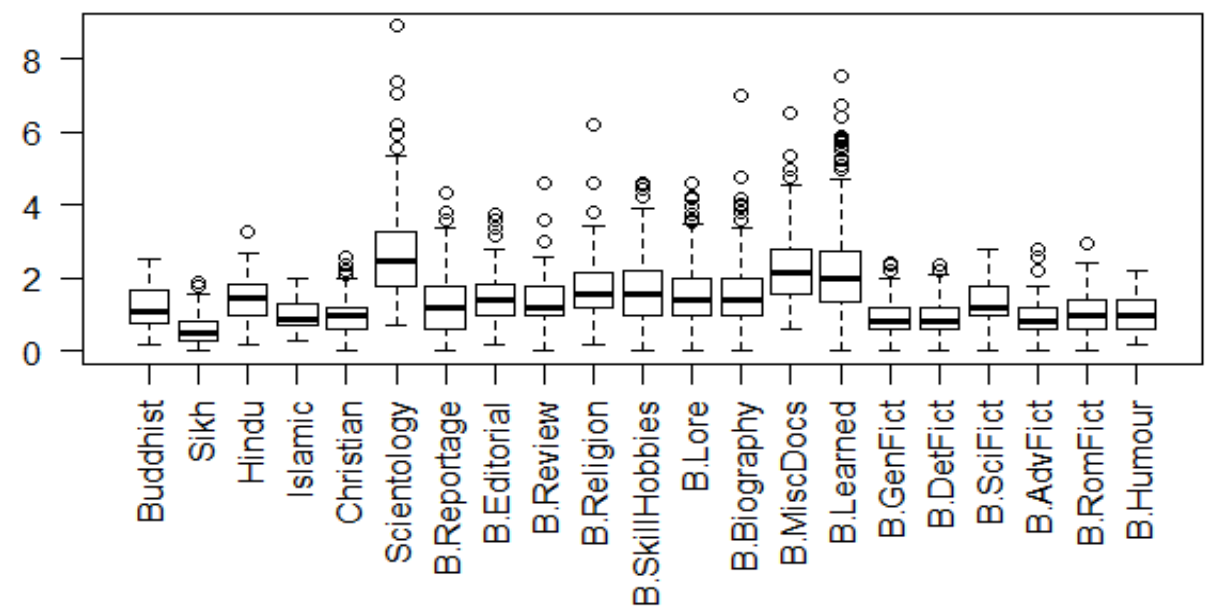

Figure 12: Extended LIWC scores for cause 


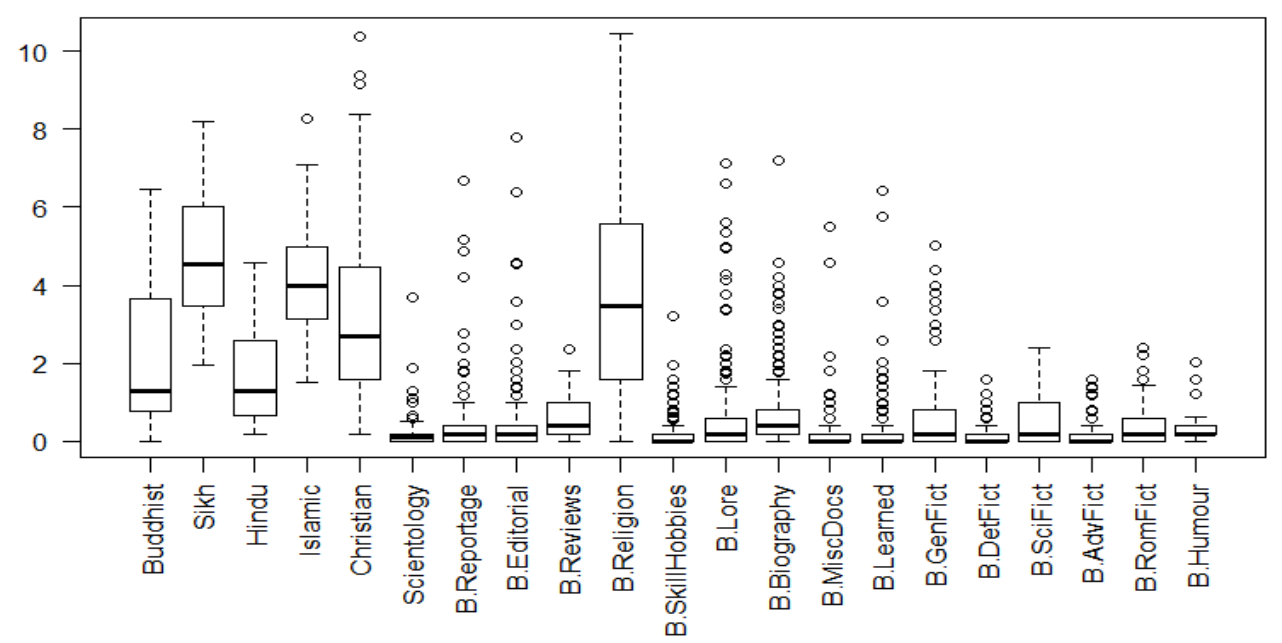

Figure 13: Extended LIWC scores for relig

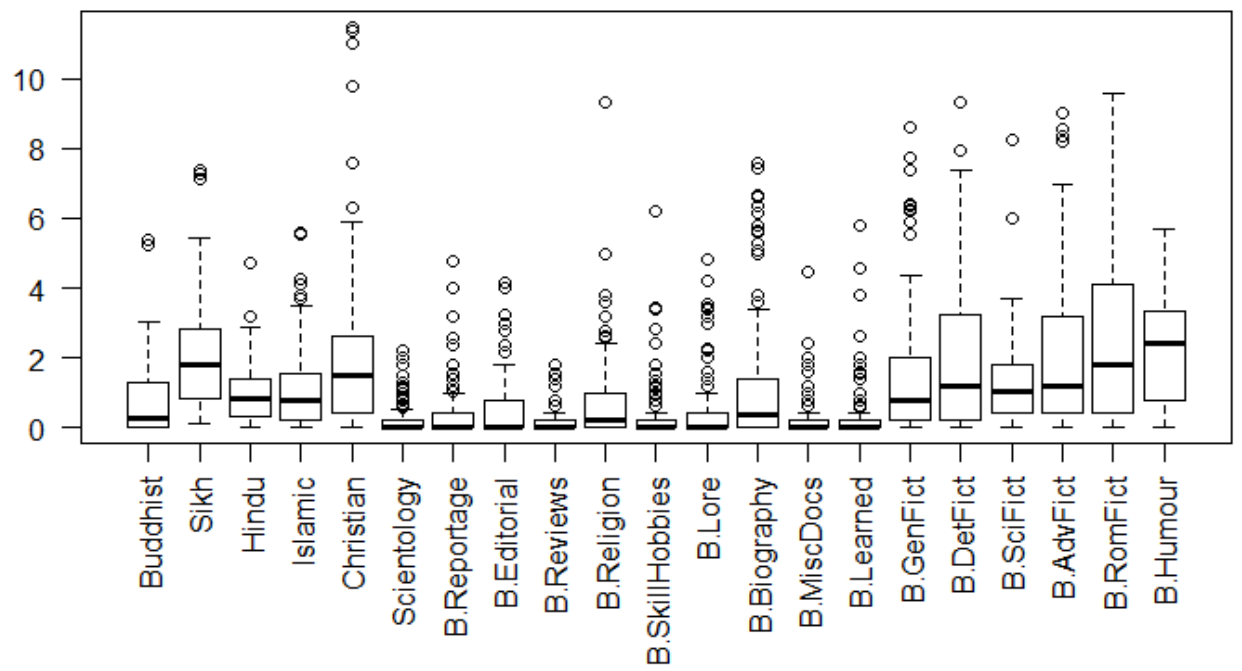

Figure 14: Extended LIWC scores for $i$

For tentat and cause, the Scientology texts scored, on average, higher than all other subcorpora, and are most comparable with the 'Learned' (academic texts) and 'DetFict' (Detective Fiction) genres for tentat, and the 'Learned' and 'MiscDocs' (Miscellaneous Documents) genres for cause. For $i$, Scientology was again comparable with 'Learned' and 'MiscDocs' but also with 'Reviews' and 'SkillHobbies' (Skills and Hobbies texts). In short, the Scientology texts appear to use tentative language such as 'perhaps' and 'maybe' very often, more than is used even in academic writing and detective fiction. The high use of 
‘causation’ words ('because', 'effect') and low use of I-words also suggest an objective, academic style of language.

The fact that the Scientology texts are deficient in 'religious' language, moreso than any other genre, is something of a threat to our hypothesis. The high score for the 'Religion' section of the Brown corpus confirms that the translated texts of the five major world religions on the left are, despite their many differences, linked by some aspect of the language of their scriptures; their scores are not the same, but each is comparable to at least one other in the group, or somewhat comparable with the 'Religion' section of the Brown corpus, and this is something the Scientology texts do not share.

However, what becomes apparent is that the religious texts do not all tend to agree with each other. As a Shapiro-Wilks normality test showed the data to be unevenly distributed ( $<$ 0.05), and as each corpus is a different size, the non-parametric KruskalWallis one-way ANOVA test was chosen for the simultaneous comparison of the six religious corpora across the main LIWC dimensions. It was found that the Scientology corpus was indeed the most 'unique' of all six, but only just; out of the 56 dimensions examined, there were 18 for which Scientology was significantly different $(p<0.01)$ from all other religious corpora, 17 for Islam ( $\mathrm{p}<0.02), 12$ for Buddhism ( $<$ 0.02), 12 for Sikhism ( $<$ 0.03), 11 for Christianity $(\mathrm{p}<0.02)$ and one for Hinduism $(\mathrm{p}<0.005)$. See Appendix C for the different dimensions in which each corpus was ‘unique', i.e. significantly different from all other religious texts.

\subsubsection{The keywords analysis}

In an attempt to 'unlock' the explanations behind the LIWC figures, we turn to the keywords of each of the religious corpora ('key' in the sense proposed by Scott (1997): having unusual frequencies - in this case, unusually high ones). In contrast with a top-down, 
dictionary-based approach such as LIWC, in which the most relevant words and themes are pre-determined by the creators of those dictionaries, the 'keyness' is decided by an algorithm and is thus "insulated from researcher bias” (Groom, 2010: 60). We acknowledge that this algorithm is also pre-determined, and of course keywords are not perfect by any means; they are simply used here as a more bottom-up approach to text analysis, in which neither a team of psychologists (as in LIWC) nor the end user (the researcher) decides which terms are worth investigating. Of course, no study is entirely free from human bias. However, religion is a notoriously subjective topic, and we need to be able to put aside, as far as possible, any personal presuppositions on the nature of Scientology and other religions. A keywords analysis was therefore chosen as a more objective way of analysing the texts, allowing us to approach Scientology texts as a "discourse community" (Bondi, 2010: 7), albeit the product of one man.

In this case, a closed-class keyword (CCK) analysis was opted for, on the basis that compared with a traditional, open-class keyword analysis - it will i) cover a larger proportion of the text, ii) produce a more manageable number of keywords to investigate, and iii) present more scope for phraseological study (Groom, 2010). This final point is particularly important when we consider that a closed-class word such as 'of' or 'with' has far more phraseological potential than an open-class word such as 'God' or 'universe' and will present us with far more patterns in a concordance.

Using freeware concordance package AntConc (Anthony, 2011), keywords for all the religious subcorpora were generated ${ }^{8}$. Tables 3 to 8 , below, give the top twenty keywords for each. The first column represents the keywords when compared against the 'Religious' corpus (Buddhist, Sikh, Hindu, Islamic, Christian and Scientology texts) and the second column gives the keywords when compared against the Brown corpus. Rather than observing

\footnotetext{
${ }^{8}$ Using the log-likelihood keyness measure
} 
a predefined number of CCKs, the aim was to see how many of them occurred in the first twenty keywords. CCKs are in bold below.

\begin{tabular}{|l|l|l|l|r|r|l|}
\hline \multicolumn{3}{|c|}{ Compared against religious texts } & \multicolumn{3}{|c|}{ Compared against Brown corpus } \\
\hline$\#$ & Freq. & Keyness & Keyword & Freq. & \multicolumn{1}{c|}{ Keyness } & \multicolumn{1}{|c|}{ Keyword } \\
\hline $\mathbf{1}$ & 1831 & 1909.951 & preclear & 1831 & 5762.233 & preclear \\
\hline $\mathbf{2}$ & 6588 & 1250.932 & a & 7737 & 4624.286 & is \\
\hline $\mathbf{3}$ & 1722 & 1233.207 & can & 787 & 2461.849 & auditor \\
\hline $\mathbf{4}$ & 7737 & 1069.232 & is & 853 & 2235.523 & communication \\
\hline $\mathbf{5}$ & 853 & 889.78 & communication & 704 & 1773.815 & universe \\
\hline $\mathbf{6}$ & 2352 & 861.789 & or & 534 & 1680.52 & thetan \\
\hline $\mathbf{7}$ & 1725 & 845.44 & an & 441 & 1387.845 & scientology \\
\hline $\mathbf{8}$ & 787 & 820.934 & auditor & 580 & 1290.508 & energy \\
\hline $\mathbf{9}$ & 704 & 593.385 & universe & 404 & 1271.405 & mest \\
\hline $\mathbf{1 0}$ & 580 & 593.064 & energy & 759 & 1135.759 & things \\
\hline $\mathbf{1 1}$ & 534 & 557.025 & thetan & 677 & 1091.87 & body \\
\hline $\mathbf{1 2}$ & 639 & 509.618 & could & 340 & 1069.994 & cannot \\
\hline $\mathbf{1 3}$ & 561 & 493.463 & space & 1722 & 1064.189 & can \\
\hline $\mathbf{1 4}$ & 539 & 476.619 & process & 327 & 1029.083 & havingness \\
\hline $\mathbf{1 5}$ & 882 & 466.188 & time & 2258 & 1020.05 & one \\
\hline $\mathbf{1 6}$ & 441 & 460.015 & scientology & 561 & 1015.76 & space \\
\hline $\mathbf{1 7}$ & 481 & 454.231 & something & 445 & 1009.63 & ability \\
\hline $\mathbf{1 8}$ & 464 & 452.372 & individual & 539 & 932.678 & process \\
\hline $\mathbf{1 9}$ & 445 & 447.275 & ability & 369 & 805.356 & scale \\
\hline $\mathbf{2 0}$ & 1006 & 435.196 & would & 3161 & 791.62 & be \\
\hline
\end{tabular}

Table 3: The keywords for the 'Scientology' corpus when compared against the 'Religious' corpus (left) and Brown corpus (right) 


\begin{tabular}{|l|l|l|l|r|r|l|}
\hline \multicolumn{3}{|c|}{ Compared against religious texts } & \multicolumn{3}{|c|}{ Compared against Brown corpus } \\
\hline$\#$ & Freq. & Keyness & Keyword & Freq. & Keyness & Keyword \\
\hline $\mathbf{1}$ & 7283 & 1191.731 & the & 7283 & 1890.206 & the \\
\hline $\mathbf{2}$ & 319 & 840.666 & practice & 319 & 1416.003 & practice \\
\hline $\mathbf{3}$ & 494 & 790.516 & should & 244 & 1390.793 & yogi \\
\hline $\mathbf{4}$ & 244 & 695.132 & yogi & 234 & 1343.055 & yoga \\
\hline $\mathbf{5}$ & 234 & 656.293 & yoga & 230 & 1319.912 & guru \\
\hline $\mathbf{6}$ & 231 & 646.68 & h & 219 & 1200.608 & buddha \\
\hline $\mathbf{7}$ & 219 & 618.206 & buddha & 494 & 1162.758 & should \\
\hline $\mathbf{8}$ & 205 & 583.555 & initiation & 205 & 1127.102 & initiation \\
\hline $\mathbf{9}$ & 180 & 465.168 & center & 330 & 1093.761 & body \\
\hline $\mathbf{1 0}$ & 178 & 442.674 & teaching & 231 & 804.826 & h \\
\hline $\mathbf{1 1}$ & 137 & 393.777 & prana & 137 & 793.813 & prana \\
\hline $\mathbf{1 2}$ & 219 & 374.19 & light & 150 & 784.948 & pray \\
\hline $\mathbf{1 3}$ & 133 & 365.766 & fierce & 178 & 751.511 & teaching \\
\hline $\mathbf{1 4}$ & 124 & 356.411 & tantra & 124 & 718.488 & tantra \\
\hline $\mathbf{1 5}$ & 150 & 352.18 & pray & 133 & 710.098 & fierce \\
\hline $\mathbf{1 6}$ & 330 & 341.174 & body & 110 & 603.165 & bliss \\
\hline $\mathbf{1 7}$ & 127 & 337.347 & ah & 127 & 595.953 & ah \\
\hline $\mathbf{1 8}$ & 133 & 329.17 & dream & 99 & 573.631 & buddhas \\
\hline $\mathbf{1 9}$ & 116 & 326.774 & central & 219 & 549.449 & light \\
\hline $\mathbf{2 0}$ & 110 & 312.058 & channel & 95 & 531.197 & illusory \\
\hline
\end{tabular}

Table 4: Keywords for the Buddhist texts

\begin{tabular}{|l|r|r|l|r|r|l|}
\hline \multicolumn{4}{|c|}{ Compared against religious texts } & \multicolumn{3}{|c|}{ Compared against Brown corpus } \\
\hline$\#$ & \multicolumn{1}{|c|}{ Freq. } & \multicolumn{1}{|c|}{ Keyness } & Keyword & Freq. & \multicolumn{1}{l|}{ Keyness } & Keyword \\
\hline $\mathbf{1}$ & 706 & 1619.957 & guru & 1383 & 7059.531 & lord \\
\hline $\mathbf{2}$ & 673 & 1574.04 & true & 706 & 3969.752 & guru \\
\hline $\mathbf{3}$ & 1383 & 1276.699 & lord & 673 & 2794.086 & true \\
\hline $\mathbf{4}$ & 328 & 896.442 & nanak & 380 & 2374.38 & o \\
\hline $\mathbf{5}$ & 580 & 830.724 & o & 433 & 1851.272 & nanak \\
\hline $\mathbf{6}$ & 433 & 729.029 & name & 253 & 1472.366 & name \\
\hline $\mathbf{7}$ & 253 & 691.463 & mehl & 411 & 1337.963 & mehl \\
\hline $\mathbf{8}$ & 220 & 601.272 & naam & 220 & 1241.707 & mind \\
\hline $\mathbf{9}$ & 195 & 532.946 & shabad & 526 & 1182.67 & your \\
\hline $\mathbf{1 0}$ & 411 & 519.415 & mind & 195 & 1100.604 & shabad \\
\hline $\mathbf{1 1}$ & 243 & 494.862 & love & 569 & 1062.27 & my \\
\hline $\mathbf{1 2}$ & 236 & 477.059 & within & 874 & 945.255 & you \\
\hline $\mathbf{1 3}$ & 951 & 448.354 & are & 296 & 925.79 & shall \\
\hline $\mathbf{1 4}$ & 167 & 436.079 & pause & 1588 & 911.307 & is \\
\hline $\mathbf{1 5}$ & 156 & 426.357 & raag & 951 & 902.461 & are \\
\hline $\mathbf{1 6}$ & 141 & 385.361 & siree & 156 & 880.483 & raag \\
\hline $\mathbf{1 7}$ & 6558 & 384.969 & the & 6558 & 834.739 & the \\
\hline $\mathbf{1 8}$ & 569 & 371.805 & my & 167 & 813.522 & pause \\
\hline $\mathbf{1 9}$ & 161 & 343.687 & grace & 141 & 795.821 & siree \\
\hline $\mathbf{2 0}$ & 124 & 338.899 & har & & & \\
\hline
\end{tabular}

Table 5: Keywords for the Sikh texts 


\begin{tabular}{|l|r|r|l|r|r|l|}
\hline \multicolumn{4}{|c|}{ Compared against religious texts } & \multicolumn{3}{|c|}{ Compared against Brown corpus } \\
\hline$\#$ & \multicolumn{1}{|c|}{ Freq. } & \multicolumn{1}{|c|}{ Keyness } & Keyword & Freq. & \multicolumn{1}{l|}{ Keyness } & Keyword \\
\hline $\mathbf{1}$ & 636 & 1532.999 & self & 636 & 2829.377 & self \\
\hline $\mathbf{2}$ & 226 & 642.112 & eternal & 271 & 1521.388 & thou \\
\hline $\mathbf{3}$ & 120 & 375.547 & yajna & 226 & 1192.616 & eternal \\
\hline $\mathbf{4}$ & 130 & 361.817 & learned & 1301 & 791.139 & is \\
\hline $\mathbf{5}$ & 150 & 316.627 & art & 120 & 727.651 & yajna \\
\hline $\mathbf{6}$ & 5217 & 292.206 & the & 117 & 674.712 & bliss \\
\hline $\mathbf{7}$ & 260 & 286.186 & through & 200 & 660.453 & o \\
\hline $\mathbf{8}$ & 174 & 283.37 & knowledge & 5217 & 650.76 & the \\
\hline $\mathbf{9}$ & 271 & 270.126 & thou & 174 & 629.839 & knowledge \\
\hline $\mathbf{1 0}$ & 118 & 262.116 & free & 111 & 574.483 & thee \\
\hline $\mathbf{1 1}$ & 183 & 229.539 & world & 205 & 533.693 & god \\
\hline $\mathbf{1 2}$ & 117 & 217.734 & bliss & 89 & 463.131 & thy \\
\hline $\mathbf{1 3}$ & 94 & 208.352 & nature & 130 & 458.124 & learned \\
\hline $\mathbf{1 4}$ & 267 & 193.673 & may & 150 & 436.457 & art \\
\hline $\mathbf{1 5}$ & 2688 & 191.937 & of & 260 & 418.593 & pure \\
\hline $\mathbf{1 6}$ & 69 & 191.37 & powers & 902.889 & through \\
\hline $\mathbf{1 7}$ & 97 & 186.203 & sun & 57 & 371.411 & soul \\
\hline $\mathbf{1 8}$ & 95 & 181.432 & real & 81 & 345.634 & vesture \\
\hline $\mathbf{1 9}$ & 57 & 178.385 & vesture & 81 & 335.384 & wise \\
\hline $\mathbf{2 0}$ & 472 & 169.022 & by & & wisdom \\
\hline
\end{tabular}

Table 6: Keywords for the Hindu texts

\begin{tabular}{|l|r|r|l|r|r|l|}
\hline \multicolumn{9}{|c|}{ Compared against religious texts } & \multicolumn{3}{l|}{ Compared against Brown corpus } \\
\hline$\#$ & \multicolumn{1}{|c|}{ Freq. } & Keyness & Keyword & Freq. & \multicolumn{1}{l|}{ Keyness } & Keyword \\
\hline $\mathbf{1}$ & 2972 & 2328.751 & god & 2972 & 9976.76 & god \\
\hline $\mathbf{2}$ & 2834 & 1510.048 & they & 3351 & 5070.076 & you \\
\hline $\mathbf{3}$ & 2355 & 1360.393 & them & 1456 & 4560.214 & shall \\
\hline $\mathbf{4}$ & 1867 & 1114.988 & we & 2355 & 4477.86 & them \\
\hline $\mathbf{5}$ & 3351 & 873.1 & you & 2834 & 3645.099 & they \\
\hline $\mathbf{6}$ & 721 & 856.267 & surely & 973 & 3329.446 & lord \\
\hline $\mathbf{7}$ & 819 & 797.161 & thou & 819 & 3203.807 & thou \\
\hline $\mathbf{8}$ & 627 & 703.26 & thee & 721 & 2615.164 & surely \\
\hline $\mathbf{9}$ & 742 & 613.766 & say & 627 & 2418.069 & thee \\
\hline $\mathbf{1 0}$ & 988 & 600.191 & those & 1867 & 2112.833 & we \\
\hline $\mathbf{1 1}$ & 1456 & 549.42 & shall & 456 & 1754.177 & thy \\
\hline $\mathbf{1 2}$ & 456 & 506.474 & thy & 988 & 1748.433 & those \\
\hline $\mathbf{1 3}$ & 320 & 430.114 & chastisement & 7334 & 1526.994 & and \\
\hline $\mathbf{1 4}$ & 344 & 404.627 & signs & 742 & 1497.787 & say \\
\hline $\mathbf{1 5}$ & 888 & 404.47 & what & 320 & 1288.137 & chastisement \\
\hline $\mathbf{1 6}$ & 291 & 387.212 & believers & 1287 & 1240.64 & who \\
\hline $\mathbf{1 7}$ & 282 & 379.038 & unbelievers & 325 & 1201.889 & unto \\
\hline $\mathbf{1 8}$ & 325 & 374.875 & unto & 282 & 1156.111 & unbelievers \\
\hline $\mathbf{1 9}$ & 330 & 348.381 & believe & 291 & 1143.663 & believers \\
\hline $\mathbf{2 0}$ & 1199 & 340.032 & their & 1920 & 1123.601 & not \\
\hline
\end{tabular}

Table 7: Keywords for the Islamic texts 


\begin{tabular}{|l|r|r|l|r|r|l|}
\hline \multicolumn{4}{|c|}{ Compared against religious texts } & \multicolumn{3}{|c|}{ Compared against Brown corpus } \\
\hline$\#$ & \multicolumn{1}{|c|}{ Freq. } & Keyness & Keyword & Freq. & Keyness & Keyword \\
\hline $\mathbf{1}$ & 992 & 836.497 & sons & 2239 & 7182.259 & lord \\
\hline $\mathbf{2}$ & 932 & 804.654 & israel & 1532 & 4065.037 & shall \\
\hline $\mathbf{3}$ & 976 & 777.337 & king & 3489 & 3930.827 & you \\
\hline $\mathbf{4}$ & 902 & 719.019 & son & 992 & 3291.872 & sons \\
\hline $\mathbf{5}$ & 1787 & 506.306 & your & 1787 & 3246.024 & your \\
\hline $\mathbf{6}$ & 569 & 502.735 & david & 932 & 3174.068 & israel \\
\hline $\mathbf{7}$ & 1369 & 477.635 & was & 976 & 2841.479 & king \\
\hline $\mathbf{8}$ & 2239 & 426.967 & lord & 1159 & 2595.14 & god \\
\hline $\mathbf{9}$ & 10275 & 379.787 & and & 902 & 2308.973 & son \\
\hline $\mathbf{1 0}$ & 542 & 379.587 & house & 10275 & 2224.67 & and \\
\hline $\mathbf{1 1}$ & 1112 & 325.335 & said & 569 & 1681.341 & david \\
\hline $\mathbf{1 2}$ & 522 & 304.454 & came & 1184 & 1200.207 & then \\
\hline $\mathbf{1 3}$ & 380 & 300.338 & offering & 1156 & 1194.288 & my \\
\hline $\mathbf{1 4}$ & 378 & 300.222 & went & 380 & 1164.154 & offering \\
\hline $\mathbf{1 5}$ & 3489 & 283.585 & you & 1330 & 1151.196 & them \\
\hline $\mathbf{1 6}$ & 489 & 281.756 & land & 1469 & 1086.017 & will \\
\hline $\mathbf{1 7}$ & 301 & 275.706 & judah & 301 & 1075.638 & judah \\
\hline $\mathbf{1 8}$ & 2329 & 259.849 & his & 1589 & 1060.356 & him \\
\hline $\mathbf{1 9}$ & 1532 & 252.23 & shall & 302 & 1038.032 & behold \\
\hline $\mathbf{2 0}$ & 708 & 249.523 & now & 307 & 1018.584 & moses \\
\hline
\end{tabular}

Table 8: Keywords for the Christian texts

Looking at the differences between the two columns, the first thing to note is that, in all cases except Scientology's, the number of CCKs in the top twenty keywords either stays the same or increases when compared against the Brown corpus (overall, an average increase of 23\%). For Scientology, it is the opposite: a drop from seven to four. Since CCKs on their own tend to reflect differences in the style, rather than the aboutness, of a text (Groom, 2010: 62), it could be said that the Scientology texts differ from 'general' language in terms of content more than style, whereas for the other religious texts the difference in style becomes more pronounced when compared with the Brown corpus than with the religious texts. This could be simply that, despite being the translations of the scriptures being produced in the mid- $20^{\text {th }}$ century, some of the archaic language is still retained. The Scientology texts, being written in 
American English around the 1960s, are also the most comparable with the Brown corpus in that respect.

The next step was to analyse the CCKs in their contexts and try to identify phraseological patterns, thus addressing the question of aboutness. Fifty concordance lines were selected at random for each CCK and were coded by the first author. Table 9 below gives each CCK, with examples of usage in the second column and tags listed on the righthand side, which represent the main patterns discovered for each CCK. These tags - rather than the CCKs themselves, due to differences in phraseology - are represented in a more visual format in Figure 15. It should be noted that this was a fairly rough, impressionistic coding scheme, developed while reading over the text, and this approach was taken in an attempt to counter the quantitative, context-independent and 'distant' (cf. Moretti, 2013) nature of LIWC and keywords analyses when used alone. 


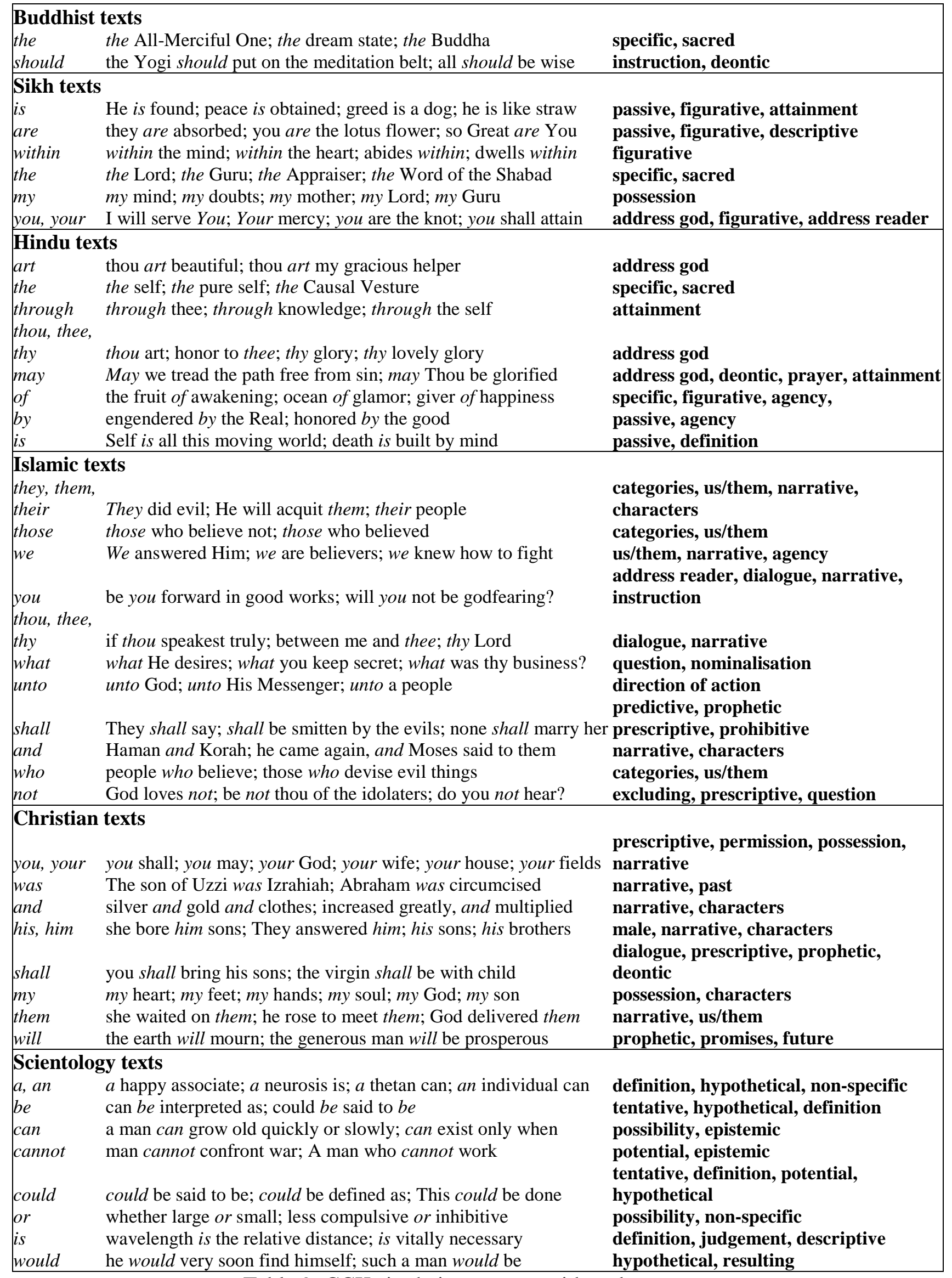

Table 9: CCKs in their contexts, with codes 
These tags are simply a form of open coding used to note observations and identify broad themes; however, these codes go a way towards uncovering the "covert message" carried by the keywords (Hunston, 2002: 119). Figure 15, below, represents the ways in which these codes are distributed across the corpora, and highlights the links between them. The font size is relative to the number of occurrences of that tag. As can be seen, there are certain codes which are central, and others which are more peripheral. Particularly striking is the high number of ties between the Christian and Islamic texts, and, to a lesser extent, between the Sikh and Hindu texts. The Buddhist texts are somewhat peripheral but still fairly well anchored to the group. The Scientology texts are the 'outsiders' here, linked only by two codes which are not central to the other religious texts. The connections between the Christian and Islamic texts should perhaps not come as a surprise when we consider that the two religions belong to the same family of Abrahamic faiths, and both scriptures pivot on narratives and characters (Renard, 2012), further reflected in the significance of 'and' as “links” in the “chain” of events (Bar-Efrat, 1980: 163). They are both, apparently, quite prescriptive in their language, using the deontic modal verb 'shall' (e.g. "You shall follow the Lord your God and fear Him”; “The fornicator shall marry none but a fornicatress”) to the extent that it is statistically key in comparison with the other religious texts.

This deontic modality is key for other mainstream religions, too; the Hindu texts feature a high number ${ }^{9}$ of the modal 'may' in the context of prayer, and the Buddhist texts refer to instructions and expectations using 'should' ${ }^{10}$. It is interesting to note that, in a study of modal verbs as markers of cultural background, Hinkel (1995: 331) finds that the modals used by those from Buddhist, Taoist and Confucian backgrounds reflect the "collective responsibility” that is key to their cultures and is not shared by Western society. For Scientology, the findings are quite different: modals such as ‘can’ and ‘would’ are used, judging from the samples observed, in a

\footnotetext{
${ }^{9} 42$ lines out of the random fifty-line sample

1046 lines out of the random fifty-line sample
} 
mostly epistemic sense ${ }^{11}$. That is, they do not tend to refer to expectations or social responsibilities, but to certainty, potential and possibilities.

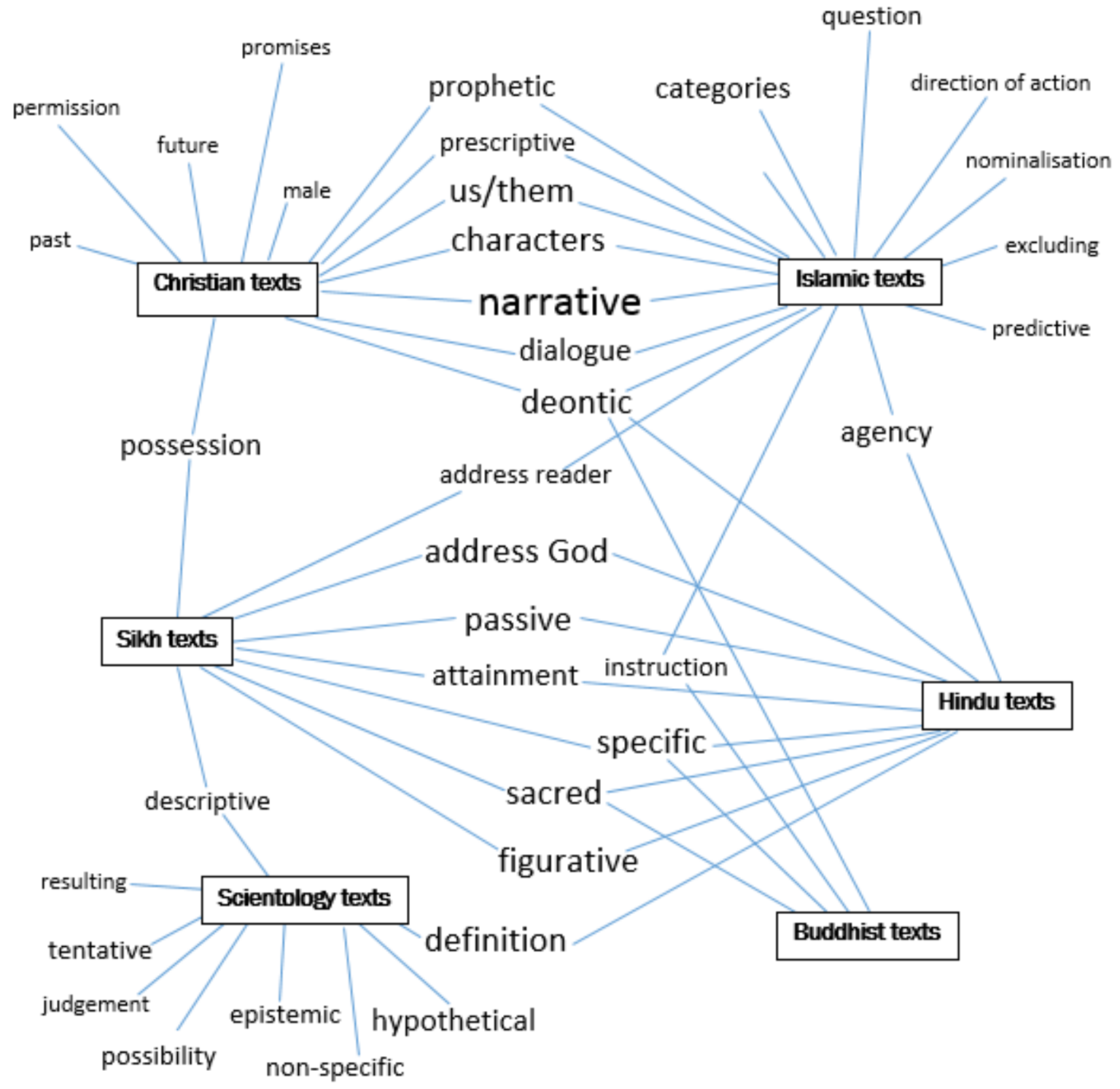

Figure 15: The codes behind the closed-class keywords

The CCK analysis also tells us that the Scientology texts are notably non-specific. For the Buddhist, Hindu and Sikh texts, their 'specific' nature is reflected by the definite article 'the' which is key for all three. Since 'the' is so common in any text, we would not expect to find it

\footnotetext{
${ }^{11} 45$ lines out of the random fifty-line sample for 'may'; 49 lines for 'would'
} 
at the top of a keywords list; either these texts have 'unusually high' occurrences of 'the', or the other texts have unusually low ones. It could be a combination of both; the keyness of ' $a$ ' and 'an' for the Scientology texts suggests that there is a real difference in the way that they refer to concepts and entities. When we look closer we can see that Scientology language revolves around definitions (probably because of the vast amount of specialist vocabulary it features) and hypothetical situations. Whereas the Hindu, Sikh and Buddhist texts talk about the Self, the Lord, and the Buddha, in a specific, often sacred way, the Scientology texts talk about $a$ thetan, an individual, and a mother-in-law, often used in everyday, hypothetical contexts. Even the key coordinating conjunction, 'or', suggests a greater element of choice and less prescriptiveness than the recurring 'and' in the Islamic and Christian texts. If we consider these as 'dimensions' in the style of Biber (1988), i.e. deontic v. epistemic modality and specific $v$. non-specific, then the Scientology texts certainly appear to be at the opposite end to those of other religions.

\subsubsection{The correspondence analysis}

Correspondence Analysis (CA) is a matrix manipulation technique for the visualisation of data sets. We start with a matrix, which is a table where the rows correspond to our text samples and the columns correspond to the linguistic features which have been chosen to characterise those texts. In this study, we make use of two types of linguistics features: LIWC categories and the most frequent individual words in the corpus. The numerical values in the matrix are the number of times a particular feature is found in a particular text sample. Initially each text sample is characterised by a large number of features, but during the CA process groups of features are found which vary together, such as the LIWC categories “insight”, “tentative”, “work”, “cause” and “achieve”, along with the punctuation mark “dash”, which occur much more frequently in the Scientology texts than the others, as shown in Figure 16. These groups of features become one pole of a "factor", while the other pole 
consists of those words which tend to be found together, or LIWC features which have similar scores, in other texts (particularly Christianity and Islam in Figure 18), such as “religion”, "they”, “I”, and "hear”. The most important (typically two) factors become the axes of a two-dimensional graph, on which both the full set of texts and the statistically significant ( $\mathrm{p}<0.1$ in this case) features characterising them can be plotted. Thus, for example, the Buddhist texts are characterised by the category “number”. We performed CA using the R statistical programming language, using the method given by Baayen (2008: 128136). Baayen regards CA as a form of clustering, where similar texts are plotted close to each other and dissimilar texts far apart. This helps us to see whether our text samples belong to logical groups of texts which are somehow similar, and to see where the Scientology texts 'sit' in relation to the others. In Figures 16 to 20, the text samples are coded as follows: Buddhist (“b”, yellow); Sikh (“g”, orange); Hindu (“h”, violet); Islamic (“k”, green); Christian (“n”, blue) and Scientology (“s”, red).

\subsubsection{Using all LIWC categories}

Figure 16 was produced by characterising the texts by the number of words in all LIWC categories, whether conceptual (such as “death”) or structural such as (“WPS”, or Words per Sentence). Using all the LIWC categories as linguistic features clearly grouped the texts by religion. 


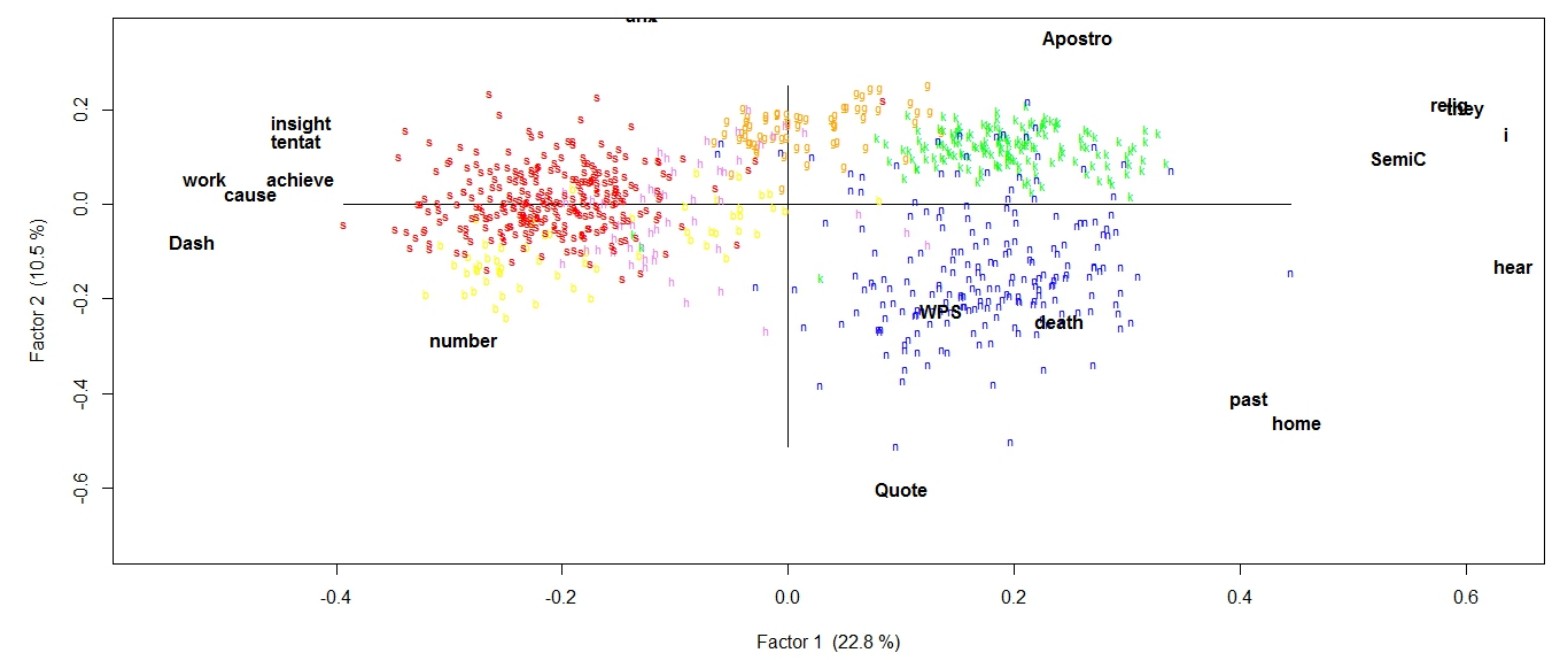

Figure 16: Correspondence Analysis produced using all LIWC categories

In Figure 16, the categories 'insight', 'tentative’, and 'cause' are clearly more salient for the Scientology texts as was found previously (see Section 3.2.1), especially 'tentative’ and 'cause' which were comparable with the scores found for the Brown corpus 'Learned', 'MiscDocs' and 'DetFict' sections. The 'achieve' and 'work' categories were also associated with Scientology texts; 'achieve' because of the high frequency of the word 'ability', for example (the Scientology texts are preoccupied with potential, ability, and what hypothetically might be), and 'work', because the LIWC category for work includes 'scien*' which of course matches all instances of 'Scientology', 'Scientologists', and 'science', too, which is a common theme. 'WPS' (Words per Sentence) was particularly associated with the Christian texts, probably due to the extent of coordination (as found in Section 3.2.2), especially that of noun phrases (1) and clauses (2):

(1) Now these are the records of the generations of Ishmael, Abraham's son, whom Hagar the Egyptian, Sarah's maid, bore to Abraham; and these are the names of the sons of Ishmael, by their names, in the order of their birth: Nebaioth, the firstborn of 
Ishmael, and Kedar and Adbeel and Mibsam and Mishma and Dumah and Massa, Hadad and Tema, Jetur, Naphish and Kedemah.

(2) The Lord said to her, "Two nations are in your womb; And two peoples will be separated from your body; And one people shall be stronger than the other; And the older shall serve the younger."

These examples, both from Genesis 25, also illustrate the high use of semi-colons (LIWC category “SemiC”), past tense (LIWC category “past”) and dialogue (LIWC categories "Quote" and "hear"), as seen in Figure 16. The LIWC category "home” is relatively frequent in the Christian texts; there appears to be a preoccupation with houses, households, the house of the Lord, and so on. The Islamic texts also feature many semi-colons and apostrophes; on closer inspection it was found that apostrophes were used instead of quotation marks, and the Koran, like the Bible, is full of dialogue. The Koran, as found in Section 3.2.2, is also heavily preoccupied with categorising, as seen from the labels of 'we', 'you', 'they' and 'I' in Figure 18. The Scientology texts overlap considerably with the Buddhist and Hindu texts - this fits with Hubbard's claims that Scientology's beliefs are rooted in Hinduism and Taoism, as outlined in Section 1. 


\subsubsection{Using only the LIWC structural features}

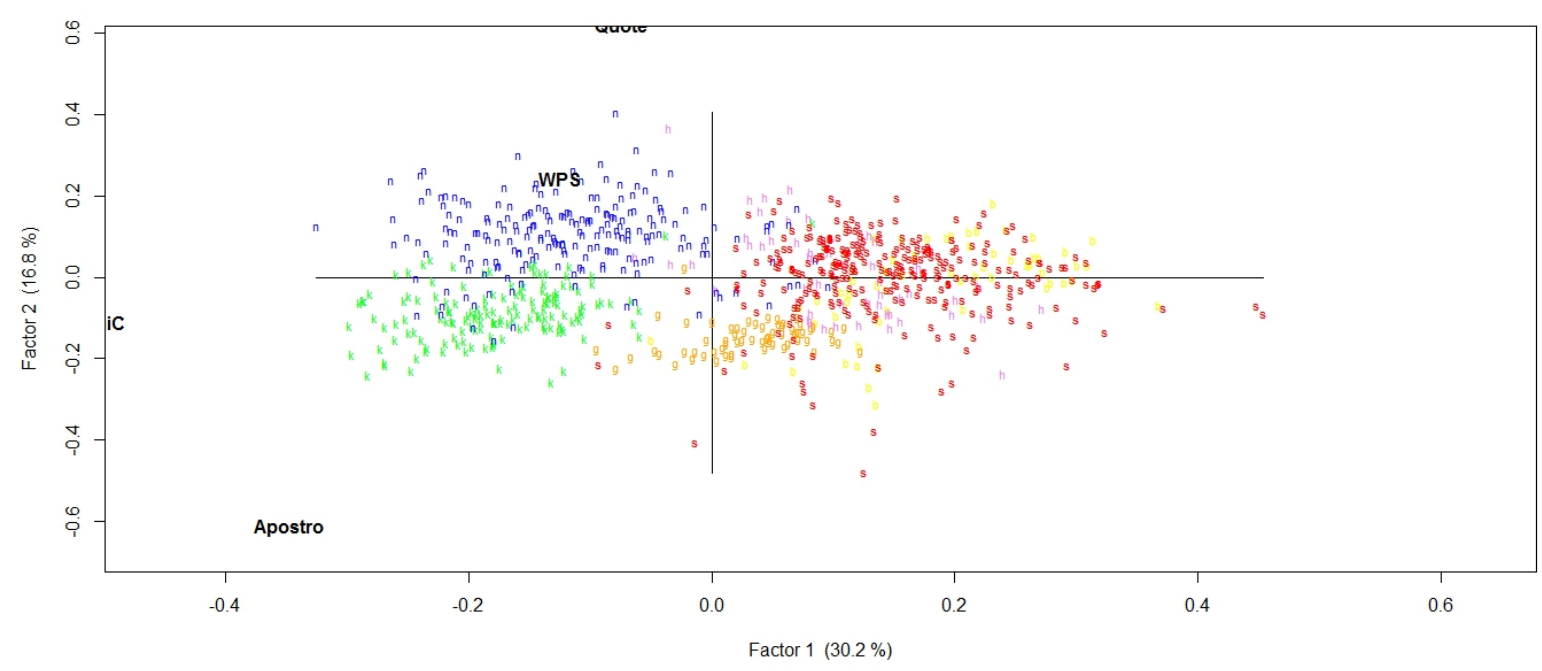

Figure 17: Correspondence Analysis using only the LIWC structural features

In our second CA experiment, only the frequencies of structural features of the LIWC categories were used to represent the texts. Our initial plot, not shown here, was very distorted, due to the presence of one outlying Scientology text which had unusual punctuation characteristics, particularly in a sentence containing scientific formulas for wavelength. Once this outlier has been removed from the analysis, once again relatively clear separation between the texts by religion was seen, as shown in Figure 17. The Christian and Islamic texts did not overlap so much as before; this may be an indication that the two corpora overlap more in terms of content than in style. The Scientology texts were more dispersed than before, but there was still much overlap with the Buddhist texts. Evidently the Scientology texts are not as consistent in their style as the other religious corpora; the Islamic, Sikh and Christian texts have stayed quite tightly grouped, in some cases more tightly grouped than they were before; is this because Scientology texts cannot make up their mind as to whether they are religious or scientific in style? There is slightly more overlap between the Scientology, Hindu and Sikh texts than before. One key grammatical word they have in 
common (as found in the CCK analysis of Section 3.2.2) is "is"; perhaps this explains the common ground. Scientology texts feature a lot of definitions ("Wavelength is the relative distance”), Hindu texts feature explanations (“the Reality—which is Being, Consciousness, Bliss, the Eternal”) and SIK texts feature passive constructions ("peace is obtained") and figurative language ("greed is a dog”), as described in Section 3.2.2. The Hindu texts are widely dispersed, as before.

\subsubsection{Using only the LIWC conceptual categories}

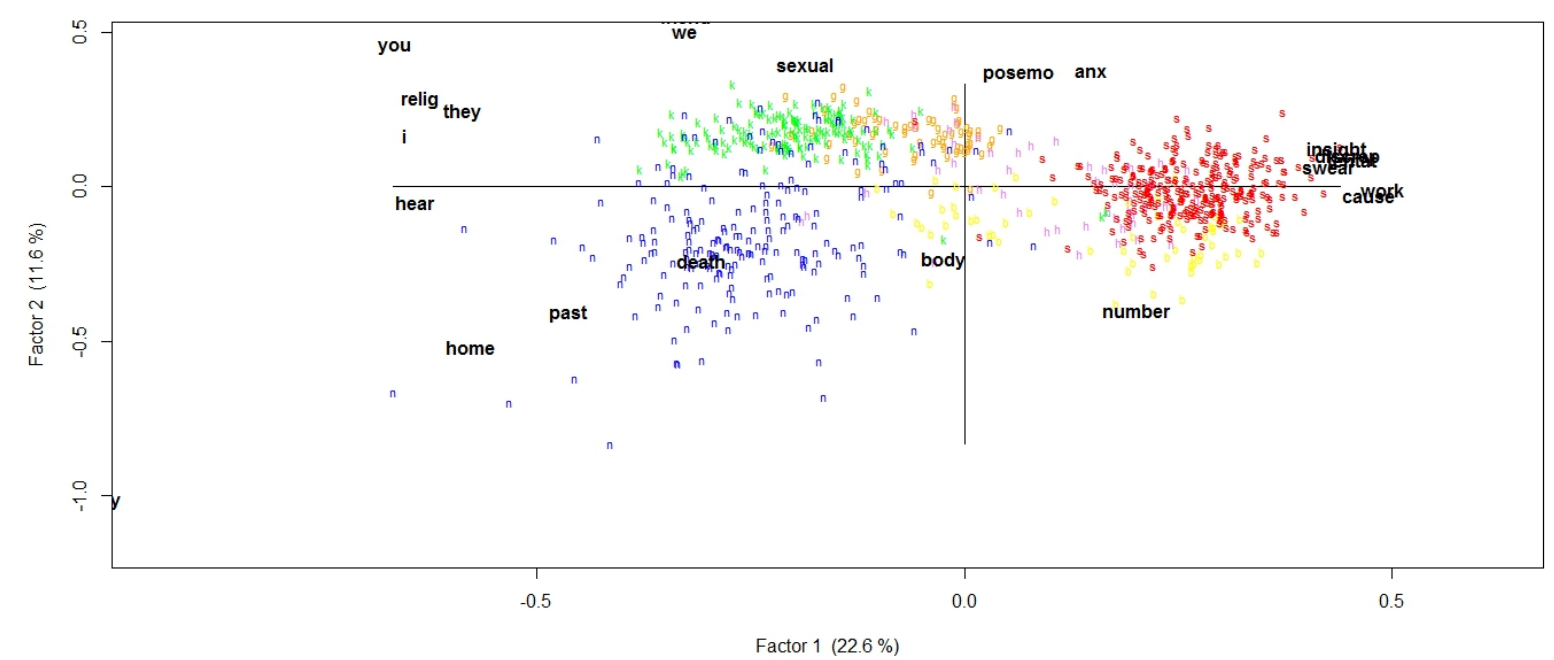

Figure 18: Correspondence Analysis using only the LIWC conceptual categories

In our third CA experiment, the texts were characterised by the frequencies with which the LIWC conceptual categories were represented. Clear clusters by religion were again obtained. The overlapping category labels near the Scientology texts are "insight”, “achieve”, "tentat”, "swear”, “work” and "cause”. This time the Christian texts were more widely dispersed. There was more overlap between the Islamic and Sikh texts than before, and even a little overlap with the Hindu texts. Does this suggest that, despite their differences in writing style, these religious texts tend to cover the same sorts of themes? The LIWC 
category "body” is perhaps most closely associated with the Buddhist texts here. The words "body” and "heart” are particularly frequent in Buddhist texts. The LIWC category "number” is again characteristic of Buddhist texts - this is mainly due to the high frequency of the word "one”. We found throughout the different analyses of this paper that the Buddhist texts (and also the Hindu texts to some extent) were particularly specific in nature; the definite article "the” was key for both, whereas for Scientology it was the indefinite articles "a” and "an”, reflecting how general, non-committal the Scientology language is. We feel that the frequent use of “one” also reflects the specific, sacred language in Buddhist texts. The Scientology texts in Figure 18 have become more tightly clustered here - clearly the texts are very consistent in terms of content, if not in terms of style. The presence of LIWC category "swear" near the Scientology texts is unfortunate, being due to the repeated use of "homo" in "homo sapiens”.

\subsubsection{Using the 50 Most Frequent Words in the corpus}

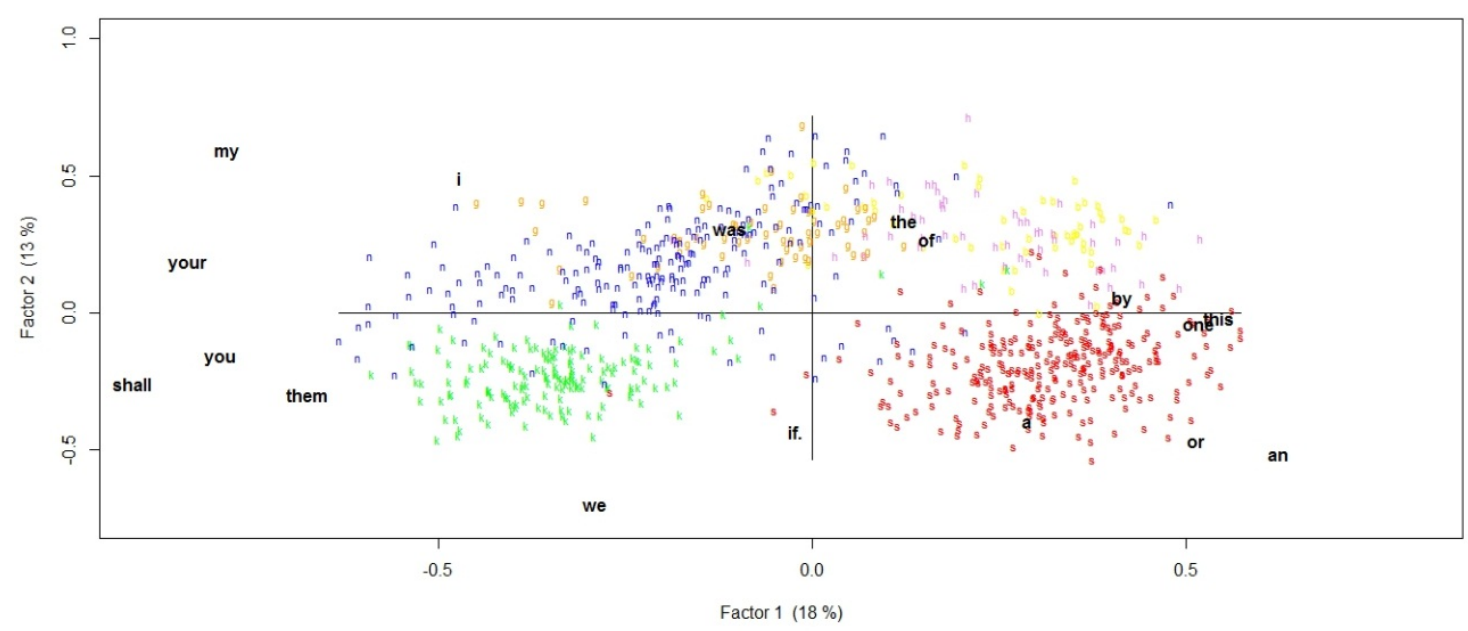

Figure 19: Correspondence Analysis using the 50 most frequent words in the corpus 
In our fourth CA experiment, we used the 50 most frequent words in the corpus as our linguistic features. The most frequent words are typically “function” words, meaning that they have grammatical functions rather than telling us about the topic of the text. They have often usefully been used to discriminate texts by author (Burrows, 1992). Of the 50 most frequent words in this corpus, two (“God” and "Lord”) were clearly not function words, so they were removed from the analysis. The results are shown in Figure 19, where all the texts more dispersed than before. There is now more overlap between the Christian and Sikh texts, due to high frequencies of "was". In the Christian texts, this was due to past events and narrative, and in the Sikh texts, possibly due to passive constructions. For the first time, the Scientology and Buddhist texts do not overlap. Here the differences between the specific, sacred nature of Buddhism and the non-specific, hypothetical nature of Scientology are particularly noticeable. Note that it was found in the CCK analysis of Section 3.2.2 that the key coordinating conjunction for Scientology is “or" (non-specific) compared with the key coordinating conjunction for the Christian and Islamic texts is "and” (specific) - although this is not seen in Figure 19. The Islamic texts remain quite distinct and their deontic nature is reflected here ("shall”), as is the recurring theme of "us and them” (“we”, "them”, and "you”) described in Section 3.2.2. The Buddhist and Hindu texts overlap slightly, as both have high frequencies of "the”, both being quite specific in nature.

In the Christian texts, "I”, “my”, and “your” are salient words, reflecting the themes of possession (“your house”, “your fields”) and personal relationships (“my God”, “my son”) in the New American Standard Bible. This analysis shows that Buddhism is clearly the closest to Scientology in linguistic style, although they are concerned with different things. 


\subsubsection{Using the 250 Most Frequent Words in the Corpus}

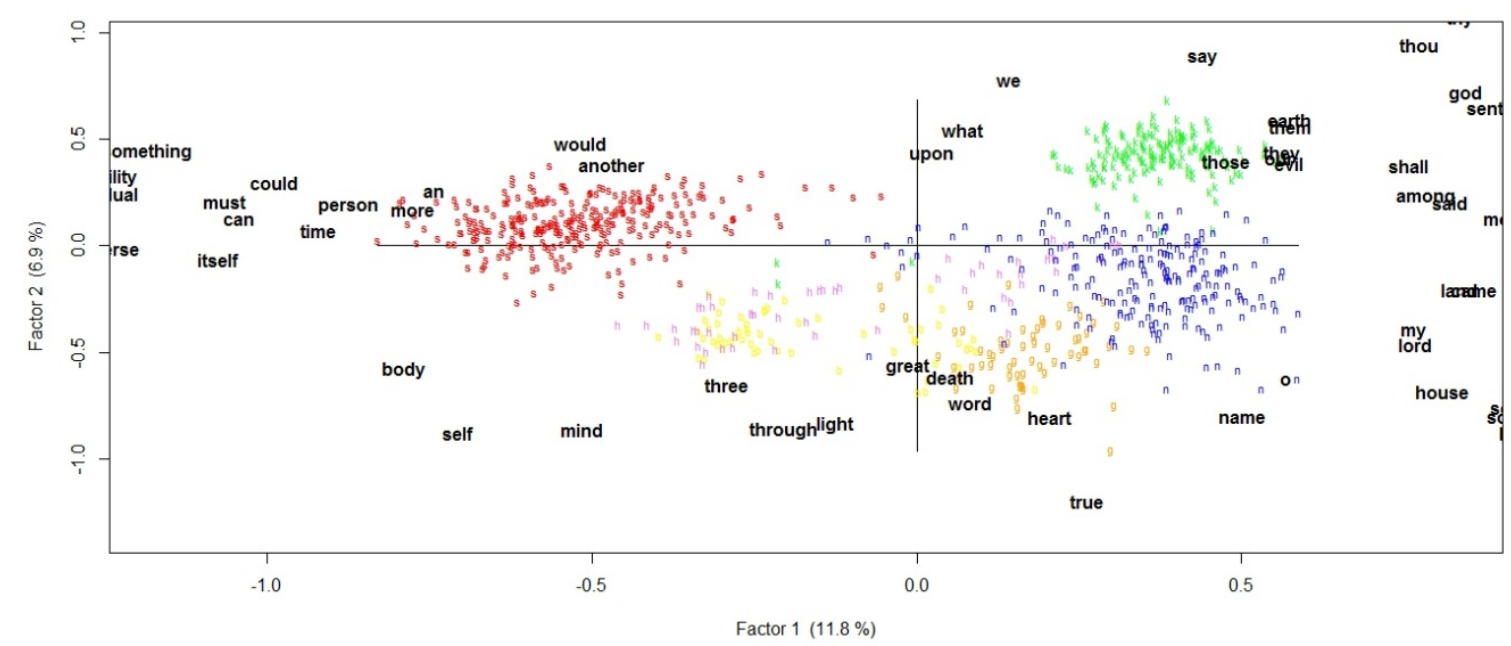

Figure 20: Correspondence Analysis using the 250 most frequent words in the corpus

In our final CA experiment, we used the 250 most frequent words in the corpus as linguistic features to characterise the texts. No attempt was made to remove the function words, but the list contained, predominantly, relatively common content words. The results are shown in Figure 20, where the Scientology and Islamic texts both form very distinct clusters. The other texts are more dispersed and overlap each other. Thus the Islamic texts show the "us and them” theme again (shown by their association with "they”, "them”, “our” and "we”), categorising language ("those” as in "those who believe not”), the theme of good and evil (“evil”), narrative and dialogue (“say”, “what”) and social obligation or deontic modality (“shall”). The Hindu and Buddhist texts share "three”, "through”, "light” and "great”, while the Sikh texts are characterised by “true”, "heart”, “word” and “death”. The Christian texts show references to possessions (“my”) such as houses (“house”) and dialogue and narrative (“said”, “and”). Finally, the Scientology texts show an uncertain, non-specific nature (“an”, “another”, “something”), along with the theme of potential (“could”, “can”, “ability”, “would”) and scientific leanings (“time”, “must”). Scientology revolves around people, lifestyles, and the everyday, which explains the presence of “person”. 


\section{Conclusions}

The LIWC, CCK and CA analyses vary in their approaches and have given us quite different results. LIWC, which searches for pre-defined dictionary items specified by a team of psychologists in the 1990s and 2000s, is arguably an unusual choice of methodology for approaching religious texts, and it does have its pitfalls: for one, phraseology is not given consideration, since it searches only for single words in isolation; and secondly, some of its conceptual dictionaries are not particularly well designed, which means that erroneous matches such as 'homo sapiens' and 'Scientology' can flag up red-herring categories such as 'swear' and 'work'. The CCK analysis and the word-based CA experiments, on the other hand, take a bottom-up, inductive approach to lexical analysis, allowing us to comment with more confidence on the themes which unite and divide different religious texts. The CCK analysis, in particular, gave the necessary attention to phraseology and opened up the discussion on conceptual common ground. In all cases, however, we must acknowledge that it is difficult to comment on differences in style when the texts being used are translations.

All of the experiments used in this study have produced interesting results. The first LIWC analysis showed that Scientology texts feature tentative and causation words at a rate comparable to academic writing and government documents, and they do not use 'religious' words in the stereotypical sense. However, judging by the disparities between all six religious corpora, it seems that there is no clear notion of a 'religious' genre or discourse community, but there are linguistic similarities between pairs or small groups of religions. The CCK analysis results revealed that, perhaps as a combination of the modal verbs Hubbard uses and his reluctance to be specific, Scientology texts have a distinctly non-committal flavour. Our CA shows that both in terms of writing style (seen when common words or LIWC structural categories are used as features to characterise the texts) and in terms of conceptual ideas (seen when less common words or LIWC conceptual categories are used as features), the 
Scientology texts are diametrically opposite the Christian and Islamic texts, with the other religious texts in intermediate positions. Although the LIWC dictionary has its shortcomings, such as its failure to take into account that words may have more than one meaning, and potential bias as a result of its top-down approach, we have demonstrated its usefulness in clustering texts in an intuitively reasonable way.

Returning to our hypothesis that Scientology can be considered a religion by analogy, there is no clear-cut answer based on these results due to the fuzziness that surrounds religious writing as a genre. However, in several ways, it appears that Scientology texts do not belong with the texts of more established religions. It is probable that, if this experiment were repeated and the data sets anonymised, the Scientology texts could be identified as the 'outsider' once again. Scientology might deal with similar concepts to other religions, but these concepts seem to be encoded in a different way. Therefore, it is not to say that Scientology is not a religion, or is not like a religion, but that it does not, from this study, look or sound particularly like any of the five major world religions, although it bears some similarities to the language of Buddhist texts. It might be that its deviation from the norm and non-committal approach to language - hypothetical theorising and rational arguments as opposed to deontic statements of social obligation - is what appeals Scientology to its growing base of followers. 


\section{References}

Anthony, L. 2011. AntConc (Version 3.2.4) [Computer Software]. Tokyo, Japan: Waseda University. http://www.antlab.sci.waseda.ac.jp/

Bar-Efrat, S. 1980. 'Some observations on the analysis of structure in biblical narrative'. Vetus Testamentum 30, pp. 154-173.

BBC News. 2013. ‘Supreme Court judges allow Scientology wedding’. [online]. Available at: http://www.bbc.co.uk/news/uk-25331754. [accessed 14 April 2014]

Biber, D. 1988. Variation across speech and writing. Cambridge: Cambridge University Press.

Bingham, J. (2013) 'Scientology is a religion, rules Supreme Court'. [online]. Available at: http://www.telegraph.co.uk/news/religion/10510301/Scientology-is-a-religion-rulesSupreme-Court.html. [accessed $7^{\text {th }}$ July 2015]

Bondi, M. 2010. 'Perspectives on keywords and keyness: an introduction’ in M. Bondi and M. Scott (eds.) Keyness in Texts, pp. 1-18. Amsterdam: John Benjamins.

Burrows, J. 1992. 'Not unless you ask nicely: The interpretative nexus between analysis and information’. Literary and Linguistic Computing 7(2): 91-109.

Enquete Commission. 1998. Final Report of the Enquete Commission on "So-called Sects and Psychogroups”: New Religious and Ideological Communities and Psychogroups in the Federal Republic of Germany. Bonn: Deutscher Bundestag.

Erwin, H. and M. Oakes. 2012. 'Correspondence Analysis of the New Testament' in Proceedings of the Workshop on Language Resource and Evaluation for Religious Texts (LRE-Rel), held in conjunction with LREC 2012. Istanbul, Turkey, May 23. 
Gledhill, C. J. 2000. Collocations in Science Writing. Tuebingen: Narr.

Groom, N. 2010. ‘Closed-class keywords and corpus-driven discourse analysis’ in M. Bondi and M. Scott (eds.) Keyness in Texts, pp. 59-78. Amsterdam: John Benjamins.

Hexham, I. 1997. 'The religious status of Scientology: is Scientology a religion?’ [online]. Available at: http://people.ucalgary.ca/ nurelweb/papers/irving/scient.html. [accessed 14 April 2014]

Hinkel, E. 1995. 'The Use of Modal Verbs as a Reflection of Cultural Values'. TESOL Quarterly, 29 (2), pp. 325-343.

Hubbard, L. R. 1954. Dianetics 55! Scientology Publications Organization.

Hunston, S. 2002. Corpora in Applied Linguistics. Cambridge: Cambridge University Press.

Kent, S. 2006. 'Scientology’s relationship with eastern religious traditions'. Journal of Contemporary Religion, 11 (1).

Lewis, J. R. 2009. Scientology. Oxford: Oxford University Press.

Mairesse, F. and M. Walker, M. 2006. 'Words mark the nerds: Computational models of personality recognition through language' in Proceedings of the 28th Annual Conference of the Cognitive Science Society, pp. 543-548.

Moretti, F. (2013) Distant Reading. Verso.

Murray, A. H. 2014. Grand Central Question: Answering the Critical Concerns of the Major Worldviews. Wheaton: InterVarsity Press.

Oakes, M. 2014. Literary Detective Work on the Computer. Amsterdam: John Benjamins. 
Pennebaker, J. W. 1997. 'Writing about emotional experiences as a therapeutic process’. Psychological Science, 8 (3), pp. 162-166.

Pennebaker, J. W., Francis, M. E. and Booth, R. J. 2007. Linguistic inquiry and word count: LIWC [Computer software]. Austin, TX: www.liwc.net.

R v Registrar General of Births, Deaths and Marriages. 2013. UKSC 77 [online]. Available at: http://supremecourt.uk/decided-cases/docs/UKSC_2013_0030_Judgment.pdf . [accessed 14 April 2014]

Renard, J. 2012. Islam and Christianity: theological themes in comparative perspective. Oakland: University of California Press.

Rowley, T. 2013. 'Scientology: church, cult or corporation?’ The Telegraph. [online]. $12^{\text {th }}$ Dec 2013. Available at: http://www.telegraph.co.uk/news/religion/10513701/Scientologychurch-cult-or-corporation.html. [accessed 14 April 2014]

Sanderson, T. 2013. 'Scientology’s dream comes true'. [online]. Available at: http://www.secularism.org.uk/blog/2013/12/scientologys-dream-comes-true. [accessed 14 April 2014]

Scientology.org. 2014. 'Scientology Definition: Official Church of Scientology Video’. [online]. Available at: http://www.scientology.org/what-is-scientology/basic-principles-ofscientology.html. [accessed 19 April 2014]

Štajner, S. and R. Mitkov, R. 2012. 'Style of Religious Texts in the 20th Century' in Proceedings of the Workshop on Language Resource and Evaluation for Religious Texts (LRE-Rel), held in conjunction with LREC 2012. Istanbul, Turkey, May 23. 
Torney, R., P. Vamplew and J. Yearwood. 2012. 'Using psycholinguistic features for profiling first language of authors'. Journal of the American Society for Information Science and Technology, 63 (6), pp. 1256-1269.

Wallis, R. 1976. The Road to Total Freedom. London: Heinemann.

Wilson, B. 1998. 'La Scientologie’ in Scientologie, pp. 111-145. Copenhagen: New Era Publications. 


\section{Appendix A: Texts used in this study}

\begin{tabular}{|c|c|c|}
\hline \multicolumn{3}{|c|}{ RELIGIOUS CORPUS } \\
\hline $\begin{array}{l}\text { Subcorpus } \\
\text { (abbr.) }\end{array}$ & $\begin{array}{l}\text { No. of } \\
\text { source } \\
\text { books }\end{array}$ & Texts used \\
\hline $\begin{array}{l}\text { Buddhist texts } \\
\text { (BUD) }\end{array}$ & 1 & $\begin{array}{l}\text { Esoteric Teachings of the Tibetan Tantra by C. A. Musés (1961) [online]. } \\
\text { Available at: http://sacred-texts.com/bud/ettt/index.htm }\end{array}$ \\
\hline $\begin{array}{l}\text { Sikh texts } \\
\text { (SIK) }\end{array}$ & 1 & $\begin{array}{l}\text { Translation of the Guru Granth Sahib by Manmohan Singh (1960). } \\
\text { [online]. Available at: http://www.gurbanifiles.org/translations/index.htm }\end{array}$ \\
\hline $\begin{array}{l}\text { Hindu texts } \\
\text { (HIN) }\end{array}$ & 2 & $\begin{array}{l}\text { The Crest-Jewel of Wisdom and other writings of Śankarâchârya: } \\
\text { translation and commentaries by Charles Johnston (1946). [online]. } \\
\text { Available at: http://sacred-texts.com/hin/cjw/index.htm } \\
\text { The Transmigration of the Seven Brahmans: a Translation from the } \\
\text { Harivansa of Langois by Henry David Thoreau (1932). [online]. } \\
\text { Available at: http://sacred-texts.com/hin/tsb/index.htm }\end{array}$ \\
\hline $\begin{array}{l}\text { Islamic texts } \\
\text { (ISL) }\end{array}$ & 1 & $\begin{array}{l}\text { The Koran Interpreted: A Translation by A. J. Arberry (1955) [online]. } \\
\text { Available at: https://archive.org/stream/QuranAJArberry/Quran- } \\
\text { A\%20J\%20Arberry djvu.txt }\end{array}$ \\
\hline $\begin{array}{l}\text { Christian texts } \\
\text { (CHR) }\end{array}$ & 66 & $\begin{array}{l}\text { The New American Standard Bible [online]. Available at: } \\
\text { http://www.biblegateway.com/versions/New-American-Standard-Bible- } \\
\text { NASB/ }\end{array}$ \\
\hline $\begin{array}{l}\text { Scientology } \\
\text { texts (SCI) }\end{array}$ & 7 & $\begin{array}{l}\text { All texts by L. Ron Hubbard. } \\
\text { Scientology 8-80 (1952); Scientology 8-8008 (1952); The Creation of } \\
\text { Human Ability (1954); Dianetics 55! (1955); Scientology: the } \\
\text { Fundamentals of Thought (1956); Problems of work (1956); } \\
\text { Scientology: a New Slant on Life (1965). }\end{array}$ \\
\hline
\end{tabular}

The Brown Corpus: A Standard Corpus of Present-Day Edited American English, for use

with Digital Computers. By W. N. Francis and H. Kucera. [online]. Available at:

http://nltk.googlecode.com/svn/trunk/nltk_data/index.xml. Manual at:

http://icame.uib.no/brown/bcm.html

All texts were used purely for the purpose of this study and were not shared with anyone else.

All accessed $1^{\text {st }}$ April 2014. 
Appendix B: LIWC dimensions and categories, taken from

http://www.kovcomp.co.uk/wordstat/LIWC.html.

\begin{tabular}{|c|c|c|}
\hline \multicolumn{3}{|c|}{ LIWC 2007 Dimensions and Sample Words } \\
\hline DIMENSION & EXAMPLES & \# WORDS \\
\hline \multicolumn{3}{|c|}{ I. STANDARD LINGUISTIC DIMENSIONS } \\
\hline Total function words & & 464 \\
\hline Total pronouns & I, them, itself & 116 \\
\hline \begin{tabular}{|c|} 
Personal pronouns \\
\end{tabular} & I, them, her & 70 \\
\hline 1st person singular & I, me, mine & 12 \\
\hline 1st person plural & we, our, us & 12 \\
\hline 2nd person & you, your, thou & 20 \\
\hline 3rd person singular & she, her, him & 17 \\
\hline 3rd person plural & they, their, they'd & 10 \\
\hline Impersonal pronouns & It, its’s those & 46 \\
\hline rticles & a, an, the & 3 \\
\hline Verbs & walk, went, see & 383 \\
\hline Auxiliary verbs & Am, will,have & 144 \\
\hline Past tense & walked, were, had & 145 \\
\hline Present tense & Is, does, hear & 169 \\
\hline Future tense & will, gonna & 48 \\
\hline Adverbs & very, really, qucikly & 69 \\
\hline Prepositions & with, above & 60 \\
\hline Conjonctions & but, whereas & 28 \\
\hline Negations & no, never, not & 57 \\
\hline Quantifiers & few, many, much & 89 \\
\hline Numbers & one, thirty, million & 34 \\
\hline Swear words & damn, fuck, piss & 53 \\
\hline \multicolumn{3}{|c|}{ II. PSYCHOLOGICAL PROCESSES } \\
\hline Social Processes & talk, us, friend & 455 \\
\hline Friends & pal, buddy, coworker & 37 \\
\hline Family & mom, brother, cousin & 64 \\
\hline Humans & boy, woman, group & 61 \\
\hline Affective Processes & happy, ugly, bitter & 915 \\
\hline Positive Emotions & happy, pretty, good & 405 \\
\hline Negative Emotions & hate, worthless, enemy & 499 \\
\hline Anxiety & nervous, afraid, tense & 91 \\
\hline Anger & hate, kill, pissed & 184 \\
\hline Sadness & grief, cry, sad & 101 \\
\hline Cognitive Processes & cause, know, ought & 730 \\
\hline Insight & think, know, consider & 195 \\
\hline Causation & because, effect, hence & 108 \\
\hline Discrepancy & should, would, could & 76 \\
\hline Tentative & maybe, perhaps, guess & 155 \\
\hline Certainty & always, never & 83 \\
\hline Inhibition & block, constrain & 111 \\
\hline Inclusive & with, and, include & 18 \\
\hline Exclusive & but, except, without & 17 \\
\hline Perceptual Processes & see, touch, listen & 273 \\
\hline
\end{tabular}




\begin{tabular}{|l|c|c|}
\hline \multicolumn{1}{|c|}{ Seeing } & view, saw, look & 72 \\
\hline Hearing & heard, listen, sound & 51 \\
\hline Feeling & touch, hold, felt & 75 \\
\hline Biological Processes & eat, blood, pain & 567 \\
\hline \multicolumn{1}{|c|}{ Body } & ache, heart, cough & 180 \\
\hline \multicolumn{1}{|c|}{ Sexuality } & clinic, flu, pill & 236 \\
\hline \multicolumn{1}{|c|}{ Ingestion } & horny, love, incest & 96 \\
\hline Relativity & eat, swallow, taste & 111 \\
\hline \multicolumn{1}{|c|}{ Motion } & area, bend, exit, stop & 638 \\
\hline \multicolumn{1}{|c|}{ Time } & walk, move, go & 168 \\
\hline III. PERSONAL CONCERNS & Down, in, thin & 220 \\
\hline Work & hour, day, oclock & 239 \\
\hline Achievement & work, class, boss & 327 \\
\hline Leisure & try, goal, win & 186 \\
\hline Home & house, TV, music & 229 \\
\hline Money & house, kitchen, lawn & 93 \\
\hline Religion & audit, cash, owe & 173 \\
\hline Death & altar, church, mosque & 159 \\
\hline IV. SPOKEN CATEGORIES & bury, coffin, kill & 62 \\
\hline Assent & & \\
\hline Nonfluencies & agree, OK, yes & 30 \\
\hline Fillers & uh, rr* & 8 \\
\hline
\end{tabular}


Appendix C: The dimensions for which each religious corpus was significantly different

from all other religious corpora, according to the Kruskal-Wallis one-way ANOVA test.

\begin{tabular}{|c|c|c|c|c|c|c|c|c|c|c|c|}
\hline $\begin{array}{l}\text { Buddhist } \\
\text { texts }\end{array}$ & $\mathrm{p}<$ & Sikh texts & $\mathrm{p}<$ & $\begin{array}{l}\text { Hindu } \\
\text { texts }\end{array}$ & $\mathrm{p}<$ & $\begin{array}{c}\text { Islamic } \\
\text { texts }\end{array}$ & $\mathrm{p}<$ & $\begin{array}{c}\text { Christian } \\
\text { texts }\end{array}$ & $\mathrm{p}<$ & $\begin{array}{c}\text { Scientolo } \\
\text { gy texts }\end{array}$ & $\mathrm{p}<$ \\
\hline body & 0.0001 & ual & 0.0001 & posemo & 0.005 & pronoun & 0.0001 & \begin{tabular}{|l|} 
relig \\
\end{tabular} & 0.01 & relig & 0.0001 \\
\hline pronoun & 0.0001 & friend & 0.03 & & & ppron & 0.0001 & pronoun & 0.0001 & ipron & 0.0005 \\
\hline we & 0.0008 & pronoun & 0.006 & & & we & 0.0001 & money & 0.0001 & article & 0.0001 \\
\hline article & 0.0004 & роsemo & 0.0001 & & & article & 0.0001 & роseто & 0.0001 & verb & 0.01 \\
\hline money & 0.0001 & affect & 0.0001 & & & verb & 0.01 & affect & 0.02 & affect & 0.002 \\
\hline negemo & 0.007 & humans & 0.005 & & & posemo & 0.005 & social & 0.0001 & quant & 0.0001 \\
\hline affect & 0.02 & social & 0.0001 & & & social & 0.0001 & past & 0.0001 & adverb & 0.0001 \\
\hline humans & 0.005 & auxverb & 0.01 & & & negate & 0.0009 & work & 0.003 & past & 0.0001 \\
\hline social & 0.0001 & work & 0.02 & & & present & 0.0001 & certain & 0.0001 & auxverb & 0.0001 \\
\hline preps & 0.001 & time & 0.01 & & & past & 0.0001 & insight & 0.0001 & space & 0.01 \\
\hline anger & 0.01 & certain & 0.003 & & & auxverb & 0.0001 & family & 0.0001 & relativ & 0.01 \\
\hline ingest & 0.0009 & cause & 0.0001 & & & anger & 0.02 & & & percept & 0.0001 \\
\hline & & & & & & work & 0.02 & & & cogmech & 0.0001 \\
\hline & & & & & & space & 0.002 & & & tentat & 0.0001 \\
\hline & & & & & & cogmech & 0.0002 & & & $\begin{array}{l}\text { cause } \\
\text { ingost }\end{array}$ & 0.0001 \\
\hline & & & & & & discrep & 0.0001 & & & family & 0.0001 \\
\hline & & & & & & & & & & $i$ & 0.0001 \\
\hline
\end{tabular}

